Western University

Scholarship@Western

Geography Publications

Geography Department

4-17-2018

\title{
The variability in the morphological active width: Results from physical models of gravel-bed braided rivers
}

Sarah Peirce

Pauline Leduc

Peter Ashmore

pashmore@uwo.ca

Follow this and additional works at: https://ir.lib.uwo.ca/geographypub

Part of the Geomorphology Commons, Physical and Environmental Geography Commons, and the Water Resource Management Commons

Citation of this paper:

Peirce, Sarah; Leduc, Pauline; and Ashmore, Peter, "The variability in the morphological active width: Results from physical models of gravel-bed braided rivers" (2018). Geography Publications. 353.

https://ir.lib.uwo.ca/geographypub/353 


\section{Earth Surface \\ Processes and Landforms}

\section{The Variability in the Morphological Active Width: Results from Physical Models of Gravel-Bed Braided Rivers}

\begin{tabular}{|r|l|}
\hline Journal: & Earth Surface Processes and Landforms \\
\hline Manuscript ID & ESP-17-0470.R1 \\
\hline Wiley - Manuscript type: & Research Article \\
\hline Date Submitted by the Author: & $29-$ Mar-2018 \\
\hline Complete List of Authors: & $\begin{array}{l}\text { Peirce, Sarah; The University of Western Ontario, Geography } \\
\text { Ashmore, Peter; University of Western Ontario, Geography } \\
\text { Leduc, Pauline; Western University, Department of Geography }\end{array}$ \\
\hline Keywords: & active width, braided river, bedload, river morphology, photogrammetry \\
\hline
\end{tabular}

SCHOLARONE $^{\text {Ix }}$

Manuscripts 


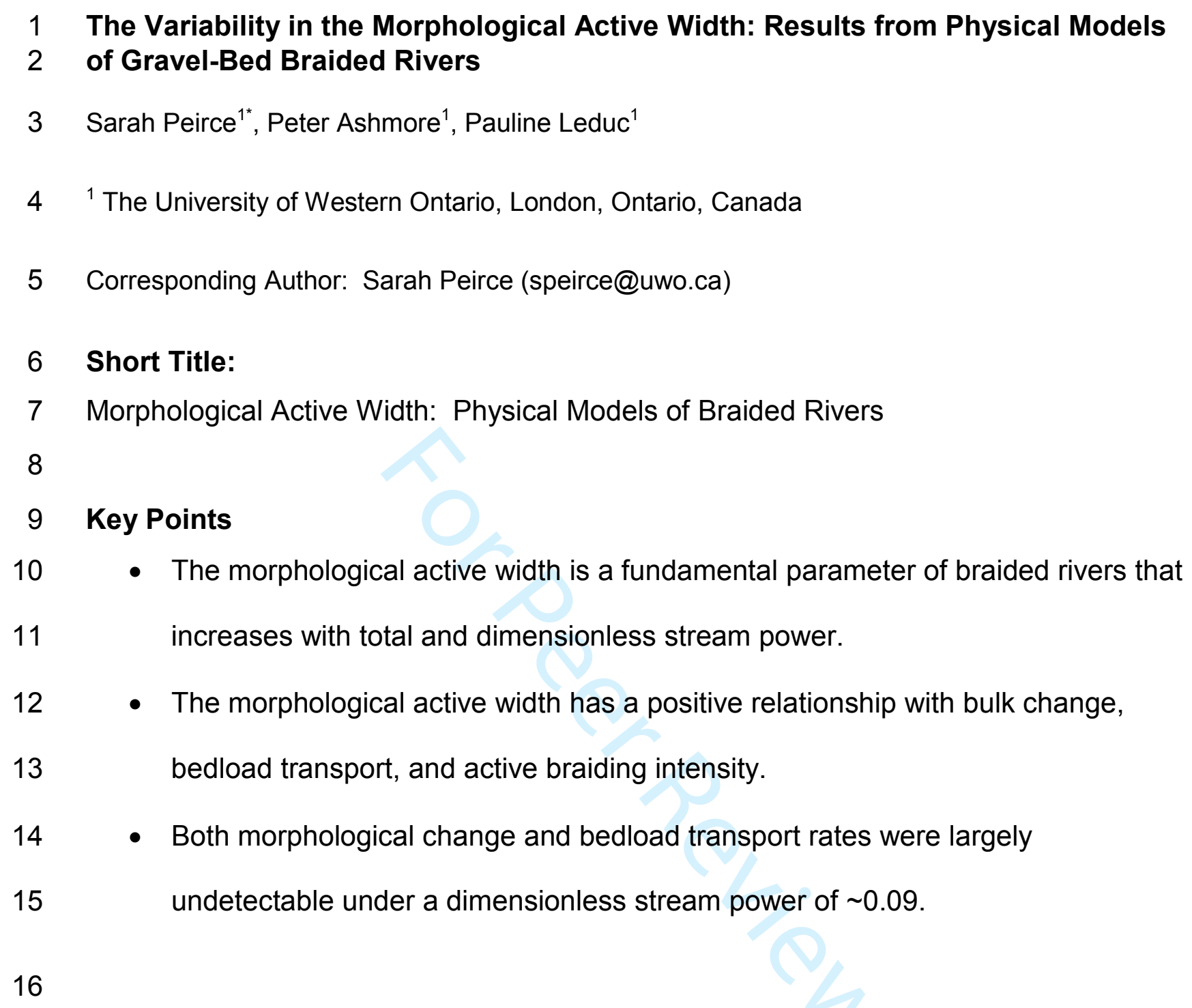




\section{Abstract}

18 The morphological active width, defined as the lateral extent of bed-material

19 displacement over time, is a fundamental parameter in multi-threaded gravel-bed rivers,

20 linking complex channel dynamics to bedload transport. Here, results are presented

21 from 5 constant discharge experiments, and three event hydrographs, covering a range

22 of flow strengths and channel configurations for which morphological change, bedload

23 transport rates, and stream power were measured in a physical model. Changes in

24 channel morphology were determined via differencing of photogrammetrically-derived

25 digital elevation models (DEMs) of the model surface generated at regular intervals over

26 the course of $\sim 115$ hours of experimental runs. Independent measures of total bedload

27 output were made using downstream sediment baskets. Results indicate that the

28 morphological active width increases with total and dimensionless stream power and is

29 strongly and positively correlated with bulk change (total volume of bed-material

30 displaced over time) and active braiding intensity ( $\mathrm{ABI})$. Although there is considerable

31 scatter due to the inherent variability in braided river morphodynamics, the active width

32 is positively correlated with independent measurements of bedload transport rate.

33 Active width, bulk change, and bedload transport rates were all negligible below a

34 dimensionless stream power threshold value of $\sim 0.09$, above which all increase with

35 flow strength. Therefore, the active width could be used as a general predictor of bulk

36 change and bedload transport rates, which in turn could be approximated from total and

37 dimensionless stream power or $\mathrm{ABI}$ in gravel-bed braided rivers. Furthermore, results

38 highlight the importance of the active width, rather than the morphological active depth,

39 in predicting volumes of change and bedload transport rates. The results contribute to

40 the larger goals of better understanding of braided river morphodynamics, creating large 
41 high-resolution datasets of channel change for model calibration and validation, and

42 developing morphological methods for predicting bedload transport rates in braiding 43 river systems.

44 Keywords: active width, braided river, bedload, river morphology, photogrammetry

\section{Introduction}

46 Observations in gravel-bed rivers indicate that bedload transport is generally restricted

47 to narrow, often discontinuous, bands of activity along the channel (Davoren and 48 Mosley, 1986; Carson and Griffiths, 1989; Haschenburger and Church, 1998; Lisle et 49 al., 2000; Ferguson, 2003). The lateral extent of these bands, the active width, is 50 spatially and temporally variable, but on average increases with stream power 51 (discharge) in stable, single-threaded channels as well as more complex, braided 52 channels (Haschenburger and Wilcock, 2003; Bertoldi et al., 2009a; Ashmore et al., 53 2011).

54 The role of the active width is of particular interest and importance in braided rivers 55 (Bertoldi et al., 2010; Ashmore et al., 2011). Braided rivers accommodate changes in 56 discharge through adjustments in wetted width and braiding intensity (BI) (i.e., number

57 of anabranches), with relatively little change in mean depth and bed shear stress 58 (Ashmore and Sauks, 2006; Bertoldi et al., 2010; Williams et al., 2015; Redolfi et al., 59 2016). As a result, bedload transport in braided rivers is more responsive to changes in 60 wetted width and active width than to changes in depth and mean bed shear stress, 61 which are the primary controls on bedload flux in single-thread channels (Bertoldi et al., 62 2009a). Although data are limited, current estimates indicate that the active width of 
63 braiding channels is rarely greater than $50 \%$ of the wetted width under channel-forming

64 conditions and, depending on relative bed particle mobility, may be as little as $10 \%$

65 (Mosley, 1987; Bertoldi et al., 2010; Ashmore et al., 2011). There is also evidence that

66 larger active width ratios (active width/ total wetted width) are associated with larger

67 active braiding intensity ( $\mathrm{ABI}$, i.e., number of anabranches transporting bedload)

68 (Bertoldi et al., 2009b; Ashmore et al., 2011) but even so, many braiding gravel-bed

69 rivers are restricted to relatively few (often less than 3 ) active channels at a given time

70 (Mosley, 1987; Egozi and Ashmore, 2009). This follows from observations in the field

71 and laboratory that indicate that a large proportion of the channel flow (up to 95\%) can

72 be conveyed by a single anabranch (Mosley, 1982; Egozi and Ashmore, 2009).

73 The active width is highly variable at a given discharge as a result of the inherent

74 instability of braided river morphology due to changes the convergence and divergence

75 of flow, and the local patterns of erosion and deposition caused by bar formation and

76 migration, as well as channel avulsion (Mosley, 1987; Bertoldi et al., 2010; Ashmore et

77 al., 2011), all of which also contribute to the variability in bedload transport rates

78 (Davies, 1987; Hoey and Sutherland, 1991; Warburton and Davies, 1994; Shvidchenko

79 and Kopaliani, 1998). These complex braiding processes are responsible for reworking

80 large portions of a braided river over a single flood event even when the active width is

81 restricted to a few channels and limited in lateral extent (Mosley, 1982, 1983; Bertoldi et

82 al., 2010).

83 Given the positive relationship between active width and $A B I$, and the fundamental

84 association with morphodynamic processes, the active width is expected to be a 85 meaningful parameter for linking complex braided river morphodynamics and the 
86 corresponding bedload transport flux (Bertoldi et al., 2009a; Ashmore et al., 2011; Lugo

87 et al., 2015; Redolfi et al., 2017). Research has already demonstrated that active width, $88 \mathrm{ABI}$, and bedload transport rates are positively correlated with dimensionless unit 89 stream power $\left(\omega^{*}\right)$ :

$$
\omega^{*}=\frac{Q S}{b \sqrt{g \Delta D_{50}^{3}}}
$$

90 where $Q$ is discharge, $S$ is slope, $D_{50}$ is median grain size, $\Delta$ is relative submerged

91 density, $b$ is the average wetted width and $g$ is the acceleration due to gravity, but these

92 relationships have not been systematically investigated (Bertoldi et al., 2009a, 2009b;

93 Ashmore et al., 2011). If robust, these relationships could provide a pathway for 94 predicting bedload transport rates, a notoriously difficult problem in gravel braided 95 rivers, in addition to contributing to understanding the wide variations in transport rate 96 that occur even under constant discharge conditions (Young and Davies, 1990; 97 Ashmore, 1991a; Hoey and Sutherland, 1991). From this, Ashmore et al. (2011) 98 searched for a general relationship for predicting the active width from simple 99 parameters that would be applicable over a range of river conditions (i.e., slope, 100 discharge, and grain size). To do this, the authors measured the active width 101 hydraulically and morphologically. The hydraulic approach was used to compute 102 instantaneous active widths, the lateral extent of grain motion, through simple 1D 103 hydraulic calculations using cross-section surveys in both physical models and full-scale 104 rivers and a standard Shields entrainment threshold. The morphological active width, 105 which represents the lateral extent of bed-material displacement over time, was 106 measured from repeat cross-sectional surveys in the field and from repeat digital 
107 elevation models (DEMs) in a physical model. Bertoldi et al. (2009a) and Ashmore et al. 108 (2011) plotted the dimensionless active width ratio (average active width/ wetted width) 109 against dimensionless stream power $\left(\omega^{*}\right)$ and uncovered a strong linear relationship 110 between the dimensionless parameters indicating that the active width is a fundamental 111 property of braided river morphodynamics. Furthermore, as dimensionless stream

112 power can be calculated from relatively little information, this relationship offers a simple 113 method for estimating active width from basic channel geometry and grain size 114 measurements (Bertoldi et al., 2009a; Ashmore et al., 2011). However, these results 115 were based on relatively few empirical measurements and a limited range of 116 dimensionless stream power and have not been consistently or systematically 117 investigated over a range of braided river morphology and discharge, or directly 118 compared to measurements of bedload flux.

119 Here, we characterize the variability in the morphological active width in gravel-bed 120 braided rivers and analyze its relationship with measurements of bedload transport 121 rates and stream power. Unlike the 'snapshot' of bedload flux defined by the 122 instantaneous active width, the morphological active width only considers the bedload 123 flux responsible for driving the evolution of channel planform and topography (Marti and 124 Bezzola, 2006; Ashmore et al., 2011). Furthermore, while the two definitions of active 125 width are expected to be comparable at sufficiently short-time intervals (Lindsay and 126 Ashmore, 2002), hydraulic predictions of active width are very sensitive to Shields 127 stress and bed material grain size, which are difficult to define for gravel-bed braided 128 rivers (Ashmore et al., 2011). Therefore, the focus here is on the connection between 129 morphological activity and the rate of bedload transport in braided rivers. Given the 
130 need for simultaneous measurements of morphological change and bedload flux, which

131 are practically impossible to obtain in the field (Bertoldi et al., 2010; Redolfi et al., 2017),

132 data was collected from physical models using a combination of digital elevation model

133 (DEM) differencing and downstream sediment baskets. The result is a large novel

134 dataset of morphological change and bedload flux across five formative discharge

135 experiments as well as three simulated event hydrographs, using spatially continuous

136 topographic data taken at high temporal frequency. The use of DEM differencing

137 techniques made it possible to quantify the morphological active width, total volumes of

138 change as well as the morphological active depth (i.e., vertical depth of morphological

139 activity), which has not yet been characterized for braided rivers, but may contribute to

140 overall understanding of river morphodynamics and morphologically-driven bedload

141 transport (Ashmore et al., 2011). By expanding the relatively limited number of

142 morphological active width measurements to date, along with introducing direct

143 measurements of bedload flux, this research has the potential to inform future

144 morphodynamic models, both conceptual and numerical, which cannot currently

145 account for the inherent complexity and morphologically-driven bedload transport of

146 braided rivers (Lugo et al., 2015; Recking et al., 2016; Williams et al., 2016b).

\section{Experimental Set-up}

148 Data was gathered from six Froude-scaled physical models of gravel-bed rivers in a 149 river modelling flume located at The University of Western Ontario (UWO). Froude-scale 150 modelling (FSM) is used in gravel-bed braided river research to preserve geometric and 151 dynamic similarity, and therefore fundamental force ratios, in the model relative to the 152 full-scale river (Ashmore and Parker, 1983; Southard et al., 1984; Ashmore, 1988, 2007; 
153 Young and Davies, 1990; Hoey and Sutherland, 1991). This includes similarity of non-

154 dimensional bed shear stress which is required in FSM for modelling bed particle 155 mobility and related morphodynamic processes (Peakall et al., 1996; Young and 156 Warburton, 1996; Ashmore, 2007; Redolfi et al., 2016). The flume was $18.3 \mathrm{~m}$ long and $1573 \mathrm{~m}$ wide with recirculating water and sediment. Five metal sediment baskets with a 158 mesh size of $0.1 \mathrm{~mm}$ were placed in the tail tank across the full width of the model 159 where all sediment output from the flume could be weighed, which allowed for the 160 calculation of a time-integrated bedload transport rate over short time intervals. To 161 maintain similarity in sediment transport and sorting processes between a full scale river 162 and the models, the grain size distribution (GSD) of the flume was scaled down at a 163 ratio of 1:35 from the Sunwapta River, a proglacial braided river located in Alberta, 164 Canada $\left(D_{50}=41 \mathrm{~mm}\right)$. The result was a model GSD that ranged from $0.18 \mathrm{~mm}$ to 16 $165 \mathrm{~mm}$, with a $D_{10}$ of $0.32 \mathrm{~mm}, D_{50}$ of $1.18 \mathrm{~mm}$ and $D_{90}$ of $3.52 \mathrm{~mm}$. To reduce cohesion 166 and non-similarity of bedforms (e.g., ripples which often form in fine sand regardless of 167 scale), the lower limit of the grain size distribution was truncated so that grains smaller 168 than $0.25 \mathrm{~mm}$ were excluded from the bulk flume grain size distribution (Young and 169 Warburton, 1996).

170 Of the six experiments completed, five were done under constant channel-forming 171 discharge conditions covering a range of total stream power $(\Omega=\rho g Q S$, where $\rho$ is 172 water density, $g$ is gravitational acceleration, $Q$ is discharge, and $S$ is slope) between $1730.10-0.41 \mathrm{~W} \mathrm{~m}^{-1}$. Labelled in chronological order, experiments $1,4,9$, and 12 were 174 completed at $1.5 \%$ slope based on the slope of the prototype river, while experiment 13 175 was completed at $2 \%$ slope in order to extend the range of total stream power (Figure 
176 1a and Table 1). A sixth experiment, experiment 11, was run in the form of three event

177 hydrographs (A, B, and C) at $1.5 \%$ slope (Figure $1 \mathrm{~b})$ where the peak model discharge of

$1782.1 \mathrm{I} \mathrm{s}^{-1}$ was chosen to reflect the average peak diurnal discharge of the Sunwapta River

$179\left(\sim 15 \mathrm{~m}^{3} \mathrm{~s}^{-1}\right)$ based on the 1:35 scaling ratio (Figure $1 \mathrm{~b}$ and Table 1) (Ashmore and

180 Sauks, 2006; Egozi and Ashmore, 2008). This peak model discharge of $2.1 \mathrm{I} \mathrm{s}^{-1}$ was

181 also used during the initial 24 hour evolution of experiment 11.

182 Each experiment began with a straight trapezoidal channel which evolved at a constant 183 channel-forming discharge towards a channel morphology with a stable average 184 braiding intensity (Ashmore, 1988, 1991b; Egozi and Ashmore, 2009; Ashmore et al., 185 2011). The initial channel dimensions were chosen to accommodate the imposed 186 discharge without causing wide-spread overbank flooding. This initial evolution 187 generally took less time as total stream power increased, with the exception of 188 experiment 1 , which developed a stable morphology after only 16 hours (Table 1). 189 Following the initial channel evolution, two $\sim 8$ hour blocks of experimental runs were 190 completed. The two blocks of runs were separated by a second, shorter period $(\sim 8$ 191 hours) of evolution and planform reconfiguration in order to capture the wide natural 192 variation of morphodynamics. For each experiment, the $\sim 16$ hours of experimental runs 193 were divided into 15 intervals, with the exception experiment 1. Morphological methods, 194 like those used here, are sensitive to the time interval between surveys, which must be 195 long enough to allow for a detectable amount of morphological change but short enough 196 that major changes in morphology are not compensated, resulting in no net vertical 197 change (Ashmore and Church, 1998; Lindsay and Ashmore, 2002; Ashmore et al., 198 2011). For this reason, 15 minutes was chosen as the shortest practical time interval to 
199 use in the flume, but was adjusted to 30 minutes for experiment 1 , which had very low, 200 almost undetectable, levels of morphological change after 15 minutes. The reported 201 observations include only the 30-minute runs from experiment 1 and the 15 -minute runs 202 from the remaining experiments $(4,9,11,12$, and 13). At the end of each 15 or 30 203 minute experimental run, the flow in the model was turned off, the surface drained 204 naturally, and the bedload collected in the downstream baskets was weighed and 205 returned to the tail tank for recirculation. Once the surface was completely drained (i.e., 206 no standing water at low points in the channel), convergent digital images of the entire 207 dry bed model surface were taken using 2 Canon T5i cameras located on a movable 208 camera trolley $\sim 3 \mathrm{~m}$ above the model surface as part of the dry bed photo survey. In 209 addition to the dry bed photo survey, photos of the wet bed surface were taken in the 210 last minute of each run, covering the downstream half $(\sim 10 \mathrm{~m})$ of the model.

\section{Data Processing and DEM Processing}

212 The software package Agisoft PhotoScan 1.0.0.1 was used for photogrammetric 213 processing to convert both the dry and wet bed photo surveys into high-resolution digital 214 elevation models (DEMs) (Kasprak et al., 2015; Morgan et al., 2016). The photo surveys 215 were batch-processed using a custom Python script, which produced an orthophoto and 216 DEM of each flume surface with $1.5 \mathrm{~mm}$ pixels, which is similar to the $D_{50}$ of the model $217(1.18 \mathrm{~mm})$.

218 A sample of wet bed orthophotos taken from each experiment were used to quantify a 219 reach-averaged braiding intensity (i.e., average number of wetted channels based on 1 220 m cross-sectional counts) and wetted width (total area of water in channels divided by 221 reach length), which was manually digitized from the orthophotos using ArcMap 10.4 
222 (Egozi and Ashmore, 2008). For the constant discharge experiments, one wet bed 223 orthophoto was digitized for every two hours of experiment runs for a total of 8 224 measurements of $\mathrm{BI}$ and wetted width each. The exception was experiment 1, where 225 only 4 orthophotos were digitized due to the stable $\mathrm{BI}$ and essentially constant wetted 226 width. For the hydrograph experiment 11, one orthophoto was digitized for each 227 discharge step for a total of 26 measurements of $\mathrm{BI}$ and wetted width.

228 Examples of final DEMs for each experiment can be seen in Figure 2, where the 229 maximum elevation is between $0.05-0.07 \mathrm{~m}$. Experiment 1 maintained a single230 threaded morphology with alternate bars throughout the length of the experiment, while 231 the rest of the experiments developed a multi-threaded braiding morphology. As 232 experiment 13 left very little of the flume surface untouched, apart from minor areas 233 near the upstream weir and several small areas by the flume edges, the experiments 234 used in this research represent the practical extremes between the low stream power 235 (experiment $1,0.10 \mathrm{~W} \mathrm{~m}^{-1}$ ) and high stream power (experiment 13, $0.41 \mathrm{~W} \mathrm{~m}^{-1}$ ) 236 conditions possible in the flume used.

237 The DEMs were used to quantify topographic change over time. The standard deviation 238 of the average vertical precision for DEMs from each experiment is given in Table 2. 239 Raw DEMs of Difference (DoD) were generated by subtracting successive DEMs 240 (Williams, 2012; Kasprak et al., 2015). An absolute threshold of 3 standard deviations $241(\sigma)$ of the vertical error was applied to each raw DoD, which assuming a normal 242 distribution corresponds to a $99.7 \%$ confidence interval (Table 2). A binary map was 243 created from each thresholded DoD by identifying cells as above (given a value of 1 ) or 244 below (given a value of 0 ) the $3 \sigma$ detection limit. A circular dilation filter with radius of 15 
245 cells $(22.5 \mathrm{~mm})$ was applied to this binary map so that ' 0 ' cells within close proximity to

246 ' 1 ' were also converted to 1 . This revised binary mask was applied to the original raw

247 DoD so that only areas classified by a ' 1 ' were included when the final change detection

248 threshold of $1 \mathrm{~mm}$ was applied. While simple spatially uniform thresholds are commonly

249 used (Vericat et al., 2017), this dilation method considers the neighbours of pixels with a

250 high probability of 'real change' and therefore was chosen to include probable areas of

251 change that would be excluded with a uniform threshold while also eliminating

252 'speckling' from the DoDs. The DoDs used for the final analysis were cropped to

253 exclude coded targets on the inside walls of the flume as well as reduce inlet effects so

254 that only the downstream $14 \mathrm{~m}$ of the model were used for further analysis.

255 The total active area, defined as the total area of the flume that had topographic (i.e.,

256 morphological) change, was measured from the DoDs as the sum of all erosion and

257 deposition cells multiplied by the cell size. The reach-averaged morphological active

258 width (AW) was then calculated for each experimental run by dividing the total active 259 area $\left(\mathrm{m}^{2}\right)$ by the reach (i.e., $14 \mathrm{~m}$ ) length:

$$
A W=\frac{\text { Active area }}{\text { Reach length }}
$$

260 By multiplying the elevations (sum of $z$ values) in the active areas of deposition and 261 active areas of erosion by the cell size it was possible to calculate a volume of 262 deposition $\left(V_{d}\right)$ and erosion $\left(V_{e}\right)$. The summed volumes of deposition represent 263 additions to sediment storage (i.e., aggradation of bars) while the summed volumes of 264 erosion represent all of the sediment moving from storage (i.e., eroding banks or bars) 265 (Wheaton et al., 2013). The total volume of morphological change, the bulk change, was 
266 then calculated for each experimental run as the sum of those volumes (Wheaton et al., 267 2013):

$$
\text { Bulk Change }=\sum V_{d}+\sum V_{e}
$$

268 Finally, reach-averaged estimates of the active depth were calculated by dividing the 269 bulk change by the total active area:

$$
\text { Active Depth }=\frac{\text { Bulk change }}{\text { Active area }}
$$

270 Results

271 The Morphological Active Width

272 The reach-averaged morphological active width was calculated for each experimental

273 run (i.e., each DoD), for a total of 399 measurements across all six experiments (Table 274 1). Examples of DoDs from the end of each constant discharge experiment are 275 presented in Figure 3. Based on a preliminary visual inspection of the DoDs, experiment 2761 had very little topographic change, even over 30 minutes of experimental run time. In 277 experiment 1 , erosion and deposition were restricted to a single main channel, with 278 erosion on the outer banks of the channel and deposition on regularly spaced alternate 279 bars. Experiment 4 and 9 showed increased complexity (i.e., greater braiding and active 280 braiding intensity) compared to experiment 1 , with some areas clearly showing at least 281 two main active channels, and contiguous areas of erosion and deposition (Figure 3). 282 Experiments 12 and 13 both had multiple active channels, extensive contiguous areas 283 of erosion and deposition, and overall greater depths of erosion and deposition 284 compared to experiments at lower discharge and total stream power (Figure 3). 
285 Example DoDs from the rising limb of hydrograph B in experiment 11 are shown in 286 Figure 4. While experiment 11 runs were completed on a braiding channel developed 287 during initial evolution, the complex channel morphology including multiple anabranches 288 flowing around mid-channel bars, does not become apparent in the DoDs until 289 discharges exceed $1.14 \mathrm{I} \mathrm{s}^{-1}$ (Figure 4). At and below this discharge, the active areas of 290 change were generally patchy, discontinuous, shallow, and small in areal extent. 291 Overall, the DoDs from both the constant discharge experiments and the hydrograph 292 experiments highlight three main trends as total stream power increased: 1) the active 293 area, and therefore the reach-averaged morphological active width, became greater; 2)

294 the active areas became more continuous and contiguous as areas of erosion and 295 deposition expanded, and 3) the maximum depths of the morphological active layer 296 increased (Figure 3 and 4).

297 Values of the reach-averaged morphological active width had an overall positive 298 relationship with total stream power, but were temporally variable within each of the 299 constant discharge experiments (Figure 5a and b). Active width was very low for 300 experiment $1(\mathrm{n}=28, \bar{x}=0.015 \mathrm{~m})$ and increased with each increase in total stream 301 power, although there was considerable overlap between the ranges in active width for 302 experiment $4(0.05-0.33 \mathrm{~m}, \mathrm{n}=65, \bar{x}=0.17 \mathrm{~m})$ and experiment $9(0.10-0.35 \mathrm{~m}, \mathrm{n}=$ $30367, \bar{x}=0.20 \mathrm{~m}$ ) (Figure $5 \mathrm{a}$ and b). Experiments 12 and 13 had much higher active 304 widths than the rest of the experiments, with averages of $0.57 \mathrm{~m}(n=64)$ and $0.80 \mathrm{~m}(\mathrm{n}$ $305=66)$, respectively.

306 As with the constant discharge experiments, the reach-averaged morphological active 307 widths increased with flow strength during the hydrographs but were variable for any 
308 given total stream power and discharge (Figure 5c). Below $0.17 \mathrm{~W} \mathrm{~m}^{-1}\left(1.14 \mathrm{I} \mathrm{s}^{-1}\right)$ there 309 was very little detectable morphological change $(\bar{x}<0.05 \mathrm{~m})$ (Figure $5 \mathrm{c}$ and d). Above $3100.17 \mathrm{~W} \mathrm{~m}^{-1}$, the mean active width, as well as its variability, generally increased with 311 increasing discharge. Compared to the constant discharge experiments, the active 312 widths from the hydrograph covered a similar range as experiments 1,4 , and 9 , again 313 highlighting the sensitivity of the active width to total stream power.

314 The frequency histograms of the morphological active width show that all observations

315 from experiment 1 fell between the narrow range of 0 and $0.05 \mathrm{~m}$ (Figure 6). The rest of 316 the experiments had frequency histograms defined by a positive skewness coefficient.

317 Experiments 9 and 13 were defined by similar skewness coefficients $(0.469$ and 0.477 , 318 respectively), while experiment 12 had several high reach-averaged active width values 319 resulting in a larger skew coefficient of 0.648 (Figure 6). With the lowest skewness 320 coefficient (0.364), experiment 4 was the closest of the multi-threaded experiments to a 321 symmetrical distribution. The hydrograph experiment 11 was also positively skewed $322($ skew $=0.523)$ due to the relative abundance $(30 \%)$ of low active width values $(<0.1 \mathrm{~m})$ 323 from the low discharge runs.

324 Matching the morphological active width measurements to corresponding average 325 wetted width measurements from the sample of digitized wet bed orthophotos, it was 326 possible to estimate a reach-averaged percent active width (Table 3). For experiment 1 , 327 which had a very narrow range of wetted widths due to the single-threaded morphology, 328 the active width only accounted for $4-9 \%$ of the average wetted area of the model. 329 Experiment 4 and 9 had similar minimum values for percent active width (7.44 and 7.60 $330 \%$, respectively), but experiment 4 had a greater average (16.5 vs $11.6 \%$ ) and 
331 maximum value ( 27.3 vs. $17.1 \%)$ than experiment 9 . This difference may be related to

332 a primary channel in experiment 9 flowing along the side of the flume for several meters

333 during the second half of the experiment, restricting the lateral development and

334 therefore the active area of the channel. As expected, experiments 12 and 13 had the

335 largest percent active widths, with the active width accounting for up to $50 \%$ of the

336 wetted width in experiment 13 (Table 3). The hydrograph experiment, experiment 11 ,

337 had the greatest range of values, as would be expected given the large range of

338 discharges, but mean and median values close to those found in experiment 9 (Table

339 3). Given that experiment 9 and 11 evolved under the same formative slope and

340 discharge conditions, this could reflect a tendency for the peak total stream power or

341 discharge to control the morphological scale at which dominant braiding processes

342 occur (Redolfi et al., 2017).

343 The Morphological Active Depth

344 Along with the morphological active width, the DoDs were used to derive reach345 averaged morphological active depth. The aim was to determine if the active depth

346 behaved in a similar way as the active width, or if the majority of morphological activity

347 in braided rivers is dominated by changes in the morphological active width (Ashmore et

348 al., 2011). Excluding experiment 1, which had very low values for reach-averaged active

349 depth, the overlap in the range of the box plots in Figure $7 a$ indicate that the mean

350 active depth is not very sensitive to the changes in total stream power between the

351 multi-threaded constant discharge experiments (experiment 4, 9, 12, and 13). In

352 general, the mean active depth increased between experiments 1, 4, and 9 from 0.002

353 to $0.005 \mathrm{~m}$ before declining under the higher total stream power conditions of 
354 experiment 12 and $13(\bar{x}=0.004 \mathrm{~m})$. This is likely the result of more complex

355 morphologies at high total stream power distributing the flow among a larger number of 356 active channels and more extensive bar networks, leading to less deep scouring in any

357 particular location even though total discharge and stream power are greater.

358 During the hydrograph experiments, the reach-averaged morphological active depth 359 increased slightly above total stream power of $0.17 \mathrm{~W} \mathrm{~m}^{-1}\left(1.14 \mathrm{I} \mathrm{s}^{-1}\right)$ before levelling off 360 around $0.27 \mathrm{~W} \mathrm{~m}^{-1}\left(1.86 \mathrm{I} \mathrm{s}^{-1}\right)$ (Figure $\left.7 \mathrm{~b}\right)$. Yet, overall range of mean active depth was 361 still small $(0.002-0.005 \mathrm{~m})$ (Figure $7 \mathrm{~b})$.

\section{Connecting Channel Morphodynamics to Bedload Transport}

363 Given that the morphological active width was more sensitive to total stream power and 364 discharge than the morphological active depth for both the constant discharge and 365 hydrograph experiments, three additional analyses were completed to see how active 366 width related to other components of channel dynamics and bedload transport. First, 367 bulk change was determined from the DoDs and compared to the morphological active 368 width to determine if the active width might be used as an indicator of total 369 morphological channel change. Second, direct measurements of bedload transport rate 370 from sediment baskets at the downstream end of the model were used to see how the 371 morphological active width corresponded to independent measures of bedload 372 transport. Finally, results from this study were non-dimensionalized to compare with 373 previous data of morphological active widths in braided rivers, specifically as they 374 related to dimensionless stream power and active braiding intensity. 


\section{Volumes of Change}

376 Bulk change, the total volume of erosion and deposition for each DoD, increased with

377 total stream power across the constant discharge experiments (Table 4). Like the

378 morphological active width, bulk change was largely undetectable for the single-

379 threaded experiment $1\left(\bar{x}=0.0006 \mathrm{~m}^{3}\right)$. Across the multi-threaded constant discharge

380 experiments, the mean bulk change increased steadily with each increase in total

381 stream power towards experiment 13 , which had the greatest mean bulk change $(\bar{x}=$ $\left.3820.047 \mathrm{~m}^{3}\right)($ Table 4$)$.

383 As expected, the bulk change was highly variable across the hydrograph experiments, 384 but overall increased with increasing discharge and total stream power. As with 385 morphological active width, mean bulk change was very low at stream power less than $3860.17 \mathrm{~W} \mathrm{~m}^{-1}\left(\bar{x}<0.001 \mathrm{~m}^{3}\right)$ and then increased with total stream power to a maximum 387 average value of $0.025 \mathrm{~m}^{3}$ at the peak stream power of $0.31 \mathrm{~W} \mathrm{~m}^{-1}\left(2.1 \mathrm{I} \mathrm{s}^{-1}\right)$. Focusing 388 on the peak total stream power runs $\left(0.31 \mathrm{~W} \mathrm{~m}^{-1}\right)$, hydrographs $\mathrm{A}$ and $\mathrm{C}$ had similar 389 average bulk change ( $\bar{x}=0.030$ and $0.032 \mathrm{~m}^{3}$ respectively) while hydrograph $\mathrm{B}$ had a 390 lower average $\left(\bar{x}=0.02 \mathrm{~m}^{3}\right)$. This result may reflect differences in hydrograph structure 391 as hydrograph $B$ had 8 consecutive peak runs while hydrographs $A$ and $C$ each only 392 had 4 . Specifically, the first 4 peak runs for hydrograph B had a very similar mean bulk 393 change $\left(\bar{x}=0.027 \mathrm{~m}^{3}\right)$ as hydrograph $A$ and $C$ while the last peak runs had an average 394 bulk change half $\left(\bar{x}=0.013 \mathrm{~m}^{3}\right)$ that of the first 4 runs. This variability within a given 395 hydrograph and between hydrographs may highlight the importance of antecedent 396 conditions and morphology in determining volumes of morphological change, and 397 ultimately bedload transport rates. 
398 The reach-averaged morphological active width was plotted against the reach-averaged 399 bulk change (bulk change volume divided by reach length) for all six experiments in 400 Figure 8. The overall relationship is strong across all of the experiments $\left(R^{2}=0.965\right.$, 401 RMSE $=0.0002)$ suggesting that active width is a good predictor of bulk change, under 402 both constant discharge and hydrograph conditions. This strong positive relationship 403 further emphasizes that the majority of the morphological activity in braided rivers is 404 dominated by changes in the morphological active width, with relatively little influence 405 from the morphological active depth.

406 Bedload Transport Rate

407 Figure 9a shows box plots for the bedload transport rates measured from the 408 downstream sediment baskets for the constant discharge experiments. Experiment 1 409 had both the lowest mean and lowest range of values $\left(\bar{x}=0.71 \mathrm{~g} \mathrm{~s}^{-1}, \sigma=0.25 \mathrm{~g} \mathrm{~s}^{-1}\right)$.

410 From there, increasing total stream power resulted in an increase in the mean bedload 411 transport rate as well as the relative variability. The average bedload transport rate for 412 experiment 4 was $2.85 \mathrm{~g} \mathrm{~s}^{-1}\left(\sigma=1.73 \mathrm{~g} \mathrm{~s}^{-1}\right)$, while experiment 9 had an average of 4.48 $413 \mathrm{~g} \mathrm{~s}^{-1}\left(\sigma=3.30 \mathrm{~g} \mathrm{~s}^{-1}\right)$. Experiments 12 and 13 had the highest averages with bedload 414 transport rates of $10.44 \mathrm{gs}^{-1}\left(\sigma=5.10 \mathrm{~g} \mathrm{~s}^{-1}\right)$ and $13.30 \mathrm{gs}^{-1}\left(\sigma=5.09 \mathrm{~g} \mathrm{~s}^{-1}\right)$ respectively 415 (Figure 9a). Following the same trend as the active width and bulk change, the mean 416 bedload transport rate and range increased above a lower threshold of $0.17 \mathrm{~W} \mathrm{~m}^{-1}(\mathrm{Q}=$ $4171.14\left(\mathrm{~s}^{-1}\right)$ and then continued to increase with increasing total stream power and 418 discharge during the hydrograph experiments (Figure 9b). Below $0.17 \mathrm{Wm}^{-1}$, measured 419 bedload transport rates were negligible $\left(\bar{x}=0.16-0.21 \mathrm{~g} \mathrm{~s}^{-1}, \sigma=0.10-0.13 \mathrm{~g} \mathrm{~s}^{-1}\right)$. 
420 Bedload transport rate has a strong positive power relationship with reach-averaged

421 morphological active width $\left(R^{2}=0.701\right.$, RMSE $\left.=3.76\right)($ Figure 10$)$. The hydrograph

422 experiment (experiment 11) covered a very similar range of values as the constant

423 discharge experiments 1,4 , and 9 , while experiments 12 and 13 extended beyond this

424 range, as expected based on differences in total stream power (Figure 10). Experiment

4251 seems to have a greater bedload transport rate than would be expected for the range

426 of active widths, which is either an artifact of the low detection rates for that experiment

427 (i.e., based on the relatively high error estimate, Table 2), or a difference in the mode of

428 transport such that bedload is less involved in dynamically developing morphology and

429 therefore behaves more like a simple, plane-bed flume (Church 2006; Recking et al.,

430 2016). The correlation of the morphological active width with directly measured bedload

431 transport rate in braided rivers at constant discharge and under varying flow conditions

432 has not previously been demonstrated.

433 The Dimensionless Morphological Active Width

434 While previous measurements of the morphological active width are relatively limited,

435 Bertoldi et al. (2009a), Ashmore et al., (2011), and Lugo et al., (2015) showed that the

436 variation of active width with discharge or total stream power may collapse to a general

437 function using dimensionless stream power $\left(\omega^{*}\right)$ and active width ratio (non-

438 dimensionalized using wetted width). Ashmore et al. (2011) also plotted the active width

439 ratio against measurements of $A B I$ in order to asses this basic relationship and to 440 evaluate whether $\mathrm{ABI}$, which can be predicted from wetted width, may be an indicator of 441 relative active width. Focusing only on measured values (not hydraulic computations),

442 the results from this research were combined with braided river results previously 
443 plotted by Ashmore et al. (2011) (Figure 11). The results from the current study help to 444 fill the large gap in previously measured conditions for gravel-bed braided rivers, which 445 included measurements from both field and flume. In terms of dimensionless stream 446 power, the results found here show a similar positive trend and range of values as those 447 previously found, particularly in terms of results from the Sunwapta River (Figure 11a). 448 The Sunwapta data cover a range of dimensionless stream power from $0.078-0.088$, 449 which appeared to be close to the approximate lower limit of dimensionless stream 450 power for non-zero active width (Ashmore et al., 2011). A similar range of 451 dimensionless stream power $(0.079-0.11)$ was found at the lower threshold of 452 morphological change $\left(\sim 0.17 \mathrm{~W} \mathrm{~m}^{-1}, \sim 1.14 \mathrm{I} \mathrm{s}^{-1}\right)$ in the hydrograph experiments, which 453 were loosely based on the diurnal hydrograph of the Sunwapta. Note that in Figure 11a, 454 the single-threaded channel (experiment 1) plots away from the rest of the experiments, 455 with a very high dimensionless stream power $(\bar{x}=0.25)$, but a low active width ratio $(\bar{x}=$ 456 0.066) (Figure 11a). This reflects a basic distinction in morphodynamics between single457 threaded and braided channels. Looking at the active width ratio and ABI (Figure 11b), 458 the results found here enhance the overall positive trend indicating that morphological 459 complexity (i.e., $\mathrm{ABI}$ ) may be a helpful indicator for morphological active width and, 460 based on Figure 8 and 10, bulk change and bedload transport rates as well. In both 461 plots, differences between the results of this research and those from previous UWO 462 experiments (Figure 11a and b) are apparent. While the previous experiments used the 463 same flume, slope, and grain size as the current data at a discharge of $2.1 \mathrm{Is}^{-1}$ (similar 464 to our experiment 9) there were differences in data collection and analysis that may 465 contribute to the discrepancies. For example, the previous survey interval was 1 hour 
466 rather than the 15 - or 30 - minute intervals used here In addition, the DoDs were

467 generated using a uniform change detection threshold of approximately $3 \mathrm{~mm}$, rather

468 than the more complex dilation method used in the current study. Finally, the

469 measurement of the water surface, and therefore the wetted width, was different

470 (estimates from cross-section topography versus mapping from orthophotos) which has

471 direct effect on the dimensionless variables.

\section{Discussion}

473 The morphological active width increased positively with total stream power and 474 discharge for both the constant discharge and hydrograph experiments, although it was 475 largely undetectable below a threshold total stream power of $0.17 \mathrm{~W} \mathrm{~m}^{-1}\left(1.14 \mathrm{I} \mathrm{s}^{-1}\right)$.

476 While there are few equivalent field observations for a known discharge or over single

477 events, Ashmore et al. (2011) found that morphological active width in the Sunwapta

478 River was largely undetectable for daily meltwater hydrographs with peak discharge 479 below $11-12 \mathrm{~m}^{3} \mathrm{~s}^{-1}$. Based in the 1:35 scaling relation between the Sunwapta and the 480 model, this corresponds with model discharge $\sim 1.5 \mathrm{I} \mathrm{s}^{-1}\left(\sim 0.2 \mathrm{~W} \mathrm{~m}^{-1}\right)$ at $1.5 \%$ slope.

481 This estimated threshold is only slightly higher than the $1.14 \mathrm{I} \mathrm{s}^{-1}\left(0.17 \mathrm{~W} \mathrm{~m}^{-1}\right)$ threshold 482 found in these physical model experiments, although the slight difference can be 483 attributed to differences in methods and morphological change detection for the 484 laboratory photogrammetry versus topographic surveys of cross-sections in the field. 485 Above this lower threshold, the morphological active width increased positively with total 486 stream power in both the field (Bertoldi et al., 2010; Ashmore et al., 2011) and flume.

487 These findings reflect a tendency for wetted width in braiding rivers to increase in 488 response to increased discharge (Ashmore and Sauks, 2006; Redolfi et al., 2016), 
489 leading to the expansion of competent flows and the morphological active width laterally 490 across the braidplain (Bertoldi et al., 2010). Furthermore, across all of the experiments 491 the average percent active width ranged from $6-45 \%$, generally increasing with total 492 stream power. This range of values reflects similar results from the field at the 493 Sunwapta River and Tagliamento River, where the percent active width generally 494 ranged from $10-40 \%$, but could reach local maximums of $50-60 \%$ (Bertoldi et al., 495 2010; Ashmore et al., 2011). Bertoldi et al.(2010) suggest that this large range in active 496 width values from barely detectable to over half of the channel width reflects changes in 497 the spatial scale at which bedload transport processes occur in braided rivers, 498 expanding from local bar and bank erosion to channel wide bifurcations and avulsions.

499 Additional experiments should investigate if percent active width is a regime property of 500 braiding rivers determined by a formative discharge.

501 Amongst the general trends, the morphological active width demonstrated high spatial 502 and temporal variability as a result of dynamic channel morphology across the multi503 threaded channel experiments, both at constant discharge and in response to imposed 504 hydrographs. Ashmore et al. (2011) attribute variability in the morphological active width 505 to the complexity of braided rivers and contingency of morphodynamic events (i.e., 506 fluctuations in $\mathrm{ABI}$, bar development, and avulsion) which are often episodic even at 507 constant discharge. Furthermore, antecedent conditions in the channel may contribute 508 to additional morphological instability through variations in local bed mobility (Ashmore 509 et al., 2011), which can be easily impacted by local grain size distributions and sediment 510 supply (Dietrich et al., 1989). Yet, even with spatiotemporal variability we were able to 
511 expand on the findings of Ashmore et al. (2011) and confirm that dimensionless stream

512 power and $\mathrm{ABI}$ can be used as general predictors of an active width.

513 Unlike the reach-averaged morphological active width, the reach-averaged

514 morphological active depth was not particularly sensitive to changes in total stream

515 power across the constant discharge experiments, and remained in a relatively narrow

516 range of $0.003-0.007 \mathrm{~m}$ for all four multi-threaded experiments (i.e., experiments 4,9 ,

517 12, and 13). Looking to the field, Vericat et al. (2017) also reported that while volumes

518 of erosion and deposition were highly variable in the braided Rees River, depths of

519 change were generally similar between flood events. Comparing the active depth

520 findings with the results of the active width confirm that increases in discharge were

521 largely accommodated by increases in the wetted width, active area (i.e., active width),

522 and active braiding intensity, with relatively little change in active depth. During the

523 hydrograph experiments there was a noticeable increase in active depth with stream

524 power above $0.17 \mathrm{~W} \mathrm{~m}^{-1}$ before leveling off under the highest total stream power

525 conditions $\left(0.31 \mathrm{~W} \mathrm{~m}^{-1}\right)$. The shift in active depth around $0.17 \mathrm{~W} \mathrm{~m}^{-1}$ could reflect the

526 transition from the below threshold condition to the above the threshold for local grain

527 entrainment.

528 Given that the morphological active depth did not respond strongly to changes in total

529 stream power, the morphological active width was plotted against bulk change and

530 direct measurements of bedload transport rate and found to have a strong positive

531 relationship in both cases. To our knowledge, these plots have not be generated before,

532 likely due to the challenges of directly, and simultaneously, measuring morphological

533 change and bedload transport rates. 
534 In addition, the results indicate that the morphological active width, bulk change, and 535 bedload transport rates all experience a similar lower threshold for detection around $5360.17 \mathrm{~W} \mathrm{~m}^{-1}\left(1.14 \mathrm{I} \mathrm{s}^{-1}, \omega^{*} \sim 0.09\right)$ indicating that in dynamic rivers, there is no significant 537 bedload transport without detectable net morphological change at the channel scale. 538 Bedload entrainment thresholds have classically been defined at the grain scale (see 539 Buffington and Montgomery, 1997) but evidence from these experiments indicate that 540 the grain-scale bedload threshold may be the same (or very similar) to the threshold for 541 detectable morphological change in braided rivers. The significance of this finding is that 542 it confirms that bedload transport in braided rivers is not simply grains exchanging on a 543 static bed, but active erosion and deposition that is both driven by, and controlled by, 544 the morphology of the river. This is new and requires assessment with data from other 545 physical models as well as field data which could extend these general relationships to 546 greater dimensionless stream power as well as explore the effect of different 547 hydrograph shapes, flood conditions (i.e., above bankfull), grain size distributions, and 548 sediment supply on the morphological active width. In relation to sediment supply in 549 particular, sediment recirculation imposed approximate input-output balance on the 550 model and it is possible that relationships may differ in situations in which input and 551 output do not balance.

552 Moving forward, the ability to define a general morphodynamic threshold coupling 553 bedload transport and morphological change would not only represent a fundamental 554 property of braiding dynamics, but has practical applications in numerical modelling, 555 estimating bedload transport rates and, in combination with recent results that show the 556 same threshold is linked to the mobilization of coarse bed material, assessing bed 
557 stability (Peirce, 2017). For example, a reach-scaled morphodynamic threshold will 558 likely be easier to characterize in the field than a local grain-scale entrainment 559 threshold, which is difficult to define due to the complex interactions between local 560 shear stress, grain size, and bed structure (Buffington and Montgomery, 1997; Yager 561 and Schott, 2013), especially in large, complex braided rivers. Therefore, general 562 morphodynamic thresholds have the potential to simplify data collection in the field as 563 well as numerical model input parameters, which currently rely on detailed grain size 564 information and entrainment thresholds (Ashmore et al., 2011). In addition, in braided 565 rivers where ecological functioning is paramount, a general threshold for bedload 566 transport and morphological change could help define the disturbance regimes and 567 spatial extent of the bed necessary for habitat restoration and management (Piegay et 568 al., 2006; Bertoldi et al., 2010).

569 Aside from the above findings, this research highlights the value and importance of 570 morphological methods and physical modelling for understanding and estimating

571 channel evolution and bedload transport rates in dynamic rivers linking braiding rivers 572 (Ashmore and Church, 1998; Williams et al., 2016b). To date, field data on braided river 573 channel topography is limited by low spatial and temporal frequency and a lack of 574 simultaneous bedload transport rates (Bertoldi et al., 2010; Church and Ferguson, 2015; 575 Williams et al., 2016b; Vericat et al., 2017). Here, the use of a physical model allowed 576 for the collection of high-resolution, spatially distributed data of braided river processes 577 and bedload transport rates that contribute to our understanding of the fundamentals of 578 braided river morphodynamics. These data and corresponding analysis can inform, 579 assess, and assist in developing numerical models of braiding morphodynamics and 
580 bedload flux (Bertoldi et al., 2009a; Williams, 2012; Church and Ferguson, 2015; Lugo 581 et al., 2015), which require calibration and validation with high-resolution 3-dimensional 582 surveys of braided rivers (Williams et al., 2016a; Redolfi et al., 2017).

583 Also, while the research here focused on braided river morphologies, Lugo et al., (2015) 584 used lateral confinement experiments in uniform sand to show that a general 585 relationship between active width (in that case, instantaneous), and dimensionless 586 stream power may not be restricted to braiding rivers, but seems to apply to 587 transitioning (i.e., wandering) as well. Additional experiments should look at these 588 relationships across a greater variety of river morphologies to see if morphodynamic 589 thresholds like those found here are unique to multi-threaded rivers. If so, they could 590 represent a new avenue for defining the transition between meandering and braiding 591 rivers, a useful tool for river channel design, restoration, and characterization (Kleinhans 592 and van den Berg, 2011). Finally, in light of advancements in high-resolution topography 593 methods (Vericat et al., 2017), it may be possible in the future to gather larger datasets 594 of active width, wetted width, and $\mathrm{ABI}$, tied to known discharge conditions, in natural 595 rivers, which can be used to further verify and scale our results.

596 Overall, we propose that future research in complex gravel-bed rivers consider 597 investigating channel-scale morphodynamic thresholds, which might be more 598 meaningful, and more efficient, in terms of understanding overall channel change and 599 bedload transport rates than thresholds strictly focused on grain-scale dynamics. From 600 here, the ability to better model and predict dynamic channel evolution and bedload 601 transport rates in braided rivers has implications for informing river management 602 decisions like those related to the assessment of flood risk, protection of infrastructure, 
603 and the restoration and preservation of ecological functioning (Marti and Bezzola, 2006;

604 Piegay et al., 2006; Williams et al., 2016b).

605 Conclusions

606 Using the largest dataset of its kind, this research highlights that the morphological

607 active width is an important attribute of braided river morphodynamics and that, while 608 spatially and temporally variable, it has a very strong positive and linear relationship 609 with total stream power, bulk change, and active braiding intensity.

610 Additionally, bedload transport rates and the morphological active width correlate across

611 a range of stream power and have similar lower thresholds of detection, allowing us to

612 conclude that bedload transport is strongly driven by morphological change in these

613 rivers, which is well characterized by active width. Furthermore, during these

614 experiments the morphological active depth was much less sensitive to changes in total

615 stream power and discharge than the morphological active width, indicating that the

616 active width is more important in terms of characterizing morphological change and

617 predicting bedload flux in braiding rivers.

618 All measures of morphological channel change (i.e., active width, active depth, and bulk

619 change) as well as bedload transport rates, were largely undetectable below the same

620 lower total stream power threshold of $0.17 \mathrm{~W} \mathrm{~m}^{-1}$ or a dimensionless stream power of

6210.09 , indicating that the bedload entrainment threshold is the same as the threshold for

622 measurable morphological change and active braiding. This defines a morphological

623 threshold for bedload transport and supports the use of reach-scale morphodynamics,

624 in which morphological active width is a central variable, rather than classical grain- 
625 scale hydraulics for analyzing bedload transport in braiding rivers. We propose that

626 future research investigate additional reach-scale morphodynamic feedback systems

627 rather than strictly grain-scale hydraulically-based models of bedload transport,

628 especially in morphologically-driven braided river systems.

629 Acknowledgements

630 This research was supported by a Natural Sciences and Engineering Research Council

631 Discovery Grant (41186-2012) to P. Ashmore. Flume construction was supported by the

632 Canada Foundation for Innovation and Newalta Resources Inc. Additional support was

633 provided by the Vanier Canada Graduate Scholarship awarded to S. Peirce. Thank you

634 to everyone who assisted with the experiments, including Lara Middleton and Danielle

635 Barr. Thank you to Karen VanKerkoerle for assisting with the graphics.

\section{References}

637 Ashmore P. 1988. Bed load transport in braided gravel-bed stream models. Earth

638 Surface Processes and Landforms 13: 677-695.DOI: 10.1002/esp.3290130803

639 Ashmore P. 1991a. Channel Morphology and Bed Load Pulses in Braided, Gravel-Bed

640 Streams. Geografiska Annaler. Series A, Physical Geography 73: 37.DOI:

$641 \quad 10.2307 / 521212$

642 Ashmore P. 1991b. How do gravel-bed rivers braid? Canadian Journal of Earth

643 Sciences 28: 326-341.DOI: 10.1139/e91-030

644 Ashmore P. 2007. Laboratory modelling of gravel braided stream morphology. Earth

645 Surface Processes and Landforms 7: 201-225.DOI: 10.1002/esp.3290070301 
646 Ashmore P, Bertoldi W, Tobias Gardner J, Gardner JT. 2011. Active width of gravel-bed

647 braided rivers. Earth Surface Processes and Landforms 36: 1510-1521.DOI:

$648 \quad$ 10.1002/esp.2182

649 Ashmore P, Church M. 1998. Sediment transport and river morphology: a paradigm for 650 study. In Gravel-Bed Rivers in the Environment , . 115-148.

651 Ashmore P, Parker G. 1983. Confluence scour in coarse braided streams. Water

652 Resources Research 19: 392-402.DOI: 10.1029/WR019i002p00392

653 Ashmore P, Sauks E. 2006. Prediction of discharge from water surface width in a 654 braided river with implications for at-a-station hydraulic geometry. Water Resources

655 Research 42: 1-11.DOI: 10.1029/2005WR003993

656 Bertoldi W, Ashmore P, Tubino M. 2009a. A method for estimating the mean bed load

657 flux in braided rivers. Geomorphology 103: 330-340.DOI:

658 10.1016/j.geomorph.2008.06.014

659 Bertoldi W, Zanoni L, Tubino M. 2009b. Planform dynamics of braided streams. Earth 660 Surface Processes and Landforms 34: 547-557.DOI: 10.1002/esp

661 Bertoldi W, Zanoni L, Tubino M. 2010. Assessment of morphological changes induced 662 by flow and flood pulses in a gravel bed braided river: The Tagliamento River (Italy).

663 Geomorphology 114: 348-360.DOI: 10.1016/j.geomorph.2009.07.017

664 Buffington JM, Montgomery DR. 1997. A systematic analysis of eight decades of 665 incipient motion studies, with special reference to gravel-bedded rivers. Water 666 Resources Research 33: 1993-2029.DOI: 10.1029/96WR03190 
667 Carson MA, Griffiths GA. 1989. Gravel transport in the braided Waimakariri River:

668 Mechanisms, measurements and predictions. Journal of Hydrology 109: 201-220.DOI:

$669 \quad 10.1016 / 0022-1694(89) 90016-4$

670 Church M, Ferguson RI. 2015. Morphodynamics: Rivers beyond steady state. Water

671 Resources Research 51: 1883-1897.DOI: 10.1002/2014WR016862

672 Davies T. 1987. Problems of bed load transport in braided gravel-bed rivers. In

673 Sediment Transfer in Gravel-Bed Rivers, Thorne CR, Bathurst JC, and Hey RD (eds).

674 John Wiley \& Sons; 793-811.

675 Davoren A, Mosley MP. 1986. Observations of bedload movement, bar development

676 and sediment supply in the braided Ohau river. Earth Surface Processes and

677 Landforms 11: 643-652.DOI: 10.1002/esp.3290110607

678 Dietrich WE, Kirchner JW, Ikeda H, Iseya F. 1989. Sediment supply and the

679 development of the coarse surface layer in gravel-bedded rivers. Nature 340: 215

680 217.DOI: $10.1038 / 340215 \mathrm{a} 0$

681 Egozi R, Ashmore P. 2008. Defining and measuring braiding intensity. Earth Surface

682 Processes and Landforms 33: 2121-2138.DOI: 10.1002/esp.1658

683 Egozi R, Ashmore P. 2009. Experimental analysis of braided channel pattern response

684 to increased discharge. Journal of Geophysical Research 114: F02012.DOI:

685 10.1029/2008JF001099

686 Ferguson RII. 2003. The missing dimension: Effects of lateral variation on 1-D

687 calculations of fluvial bedload transport. Geomorphology 56: 1-14.DOI: 10.1016/S0169- 
$688555 \times(03) 00042-4$

689 Haschenburger JK, Church M. 1998. Bed material transport estimated from the virtual

690 velocity of sediment. Earth Surface Processes and Landforms 23: 791-808.DOI:

691 10.1002/(SICI)1096-9837(199809)23:9<791::AID-ESP888>3.0.CO;2-X

692 Haschenburger JK, Wilcock PR. 2003. Partial transport in a natural gravel bed channel.

693 Water Resources Research 39: 1-9.DOI: 10.1029/2002WR001532

694 Hoey TB, Sutherland AJ. 1991. Channel morphology and bedload pulses in braided

695 rivers: a laboratory study. Earth Surface Processes and Landforms 16: 447-462.DOI:

$696 \quad 10.1002 /$ esp.3290160506

697 Kasprak A, Wheaton JM, Ashmore P, Hensleigh JW, Peirce S. 2015. The relationship

698 between particle travel distance and channel morphology: Results from physical models

699 of braided rivers. Journal of Geophysical Research: Earth Surface 120: 55-74.DOI:

$700 \quad 10.1002 / 2014 J F 003310$

701 Kleinhans MG, van den Berg JH. 2011. River channel and bar patterns explained and

702 predicted by an empirical and a physics-based method. Earth Surface Processes and

703 Landforms 36: 721-738.DOI: 10.1002/esp.2090

704 Lindsay JB, Ashmore P. 2002. The effects of survey frequency on estimates of scour

705 and fill in a braided river model. Earth Surface Processes and Landforms 27: 27-

706 43.DOI: 10.1002/esp.282

707 Lisle TE, Nelson JM, Pitlick J, Madej MA, Barkett BL. 2000. Variability of bed mobility in

708 natural, gravel-bed channels and adjustments to sediment load at local and reach 
709 scales. Water Resources Research 36: 3743-3755.DOI: 10.1029/2000WR900238

710 Lugo GAG, Bertoldi W, Henshaw AJ, Gurnell AM. 2015. The effect of lateral

711 confinement on gravel bed river morphology. Water Resources Research 51: 7145-

712 7158.DOI: 10.1002/2015WR017081

713 Marti C, Bezzola GR. 2006. Bed Load Transport in Braided Gravel-Bed Rivers. In

714 Braided Rivers: Process, Deposits, Ecology and Management, . Blackwell Publishing

715 Ltd.: Oxford, UK; 199-215.

716 Morgan JA, Brogan DJ, Nelson PA. 2016. Application of Structure-from-Motion

717 photogrammetry in laboratory flumes. Geomorphology 276: 125-143.DOI:

$718 \quad$ 10.1016/j.geomorph.2016.10.021

719 Mosley MP. 1983. Response of braided rivers to changing discharge. Journal of

720 Hydrology New Zealand 22: 18-67.

721 Mosley MP. 1987. Re: Field Measurements in a Gravel-bed River which Confirm the

722 Theory of White et al. In Sediment Transport in Gravel-Bed Rivers , . John Wiley \& Sons

723 Ltd.; 506-508.

724 Mosley MPP. 1982. Analysis of the Effect of Changing Discharge on Channel

725 Morphology and Instream Uses in a Braided River, Ohau River, New Zealand. Water

726 Resources Research 18: 800-812.DOI: 10.1029/WR018i004p00800

727 Peakall J, Ashworth PJ, Best JJLJJL. 1996. Physical Modelling in Fluvial

728 Geomorphology: Principles, Applications and Unresolved Issues. 221-253 pp.

729 Peirce SEK. 2017. Morphological Bedload Transport in Gravel-Bed Braided Rivers, The 
730 University of Western Ontario

731 Piegay H, Grant G, Nakamura F, Trustrum N. 2006. Braided River Management: from

732 Assessment of River Behaviour to Improved Sustainable Development. In Braided

733 Rivers: Process, Deposits, Ecology and Management, . Blackwell Publishing Ltd.:

734 Oxford, UK; 257-275.

735 Recking A, Piton G, Vazquez-Tarrio D, Parker G. 2016. Quantifying the Morphological

736 Print of Bedload Transport. Earth Surface Processes and Landforms 41: 809-822.DOI:

737 10.1002/esp.3869

738 Redolfi M, Guidorizzi L, Tubino M, Bertoldi W. 2017. Capturing the spatiotemporal

739 variability of bedload transport: A time-lapse imagery technique. Earth Surface

740 Processes and Landforms 42: 1140-1147.DOI: 10.1002/esp.4126

741 Redolfi M, Tubino M, Bertoldi W, Brasington J. 2016. Analysis of reach-scale elevation

742 distribution in braided rivers: Definition of a new morphologic indicator and estimation of

743 mean quantities. Water Resources Research 52: 5951-5970.DOI:

$744 \quad 10.1002 / 2015 W R 017918$

745 Shvidchenko AB, Kopaliani ZD. 1998. Hydraulic Modeling of Bed Load Transport in

746 Gravel-Bed Laba River. Journal of Hydraulic Engineering 124: 778-785.DOI:

747 10.1061/(ASCE)0733-9429(1998)124:8(778)

748 Southard JB, Smith ND, Kuhnle RA. 1984. Chutes and lobes: newly identified elements

749 of braiding in shallow gravelly streams. In Sedimentology of Gravels and

750 Conglomerates, Koster EH and Steel RJ (eds). Canadian Society of Petroleum

751 Geologists; 51-59. 
752 Vericat D, Wheaton JM, Brasington J. 2017. Revisiting the Morphological Approach. In 753 Gravel-Bed Rivers , . John Wiley \& Sons, Ltd: Chichester, UK; 121-158.

754 Warburton J, Davies T. 1994. Variability of bedload transport and channel morphology 755 in a braided river hydraulic model. Earth Surface Processes and Landforms 19: 403756 421.DOI: 10.1002/esp.3290190503

757 Wheaton JM, Brasington J, Darby SE, Kasprak A, Sear DA, Vericat D. 2013.

758 Morphodynamic signatures of braiding mechanisms as expressed through change in 759 sediment storage in a gravel-bed river. Journal of Geophysical Research: Earth Surface 760 118: $759-779 . D O I: 10.1002 / j g r f .20060$

761 Williams RD. 2012. DEMs of Difference. Geomorphological Techniques 2: 1-17.DOI: $762 \quad 2047-0371$

763 Williams RD, Brasington J, Hicks DM. 2016a. Numerical Modelling of Braided River 764 Morphodynamics: Review and Future Challenges. Geography Compass 10: 102765 127.DOI: $10.1111 / \mathrm{gec} 3.12260$

766 Williams RD, Measures R, Hicks DM, Brasington J. 2016b. Assessment of a numerical 767 model to reproduce event-scale erosion and deposition distributions in a braided river.

768 Water Resources Research 52: 6621-6642.DOI: 10.1002/2015WR018491

769 Williams RD, Rennie CD, Brasington J, Hicks DM, Vericat DD. 2015. Linking the spatial 770 distribution of bed load transport to morphological change during high-flow events in a 771 shallow braided river. Journal of Geophysical Research: Earth Surface 120: 604772 622.DOI: 10.1002/2014JF003346 
773 Yager EM, Schott HE. 2013. The Initiation of Sediment Motion and Formation of Armor

774 Layers. In Treatise on Geomorphology, Shroder JF (ed). Elsevier: San Diego; 87-102.

775 Young WJ, Davies TRH. 1990. Prediction of bedload transport rates in braided rivers: a 776 hydraulic model study. Journal of Hydrology (NZ) 29: 75-92.

777 Young WJ, Warburton J. 1996. Principles and practice of hydraulic modelling of braided 778 gravel-bed rivers. Journal of Hydrology New Zealand 35: 175-198.DOI: 10.1016/S0301779 9322(97)80098-5

780

781 
782 Table 1 - Experimental conditions where the experiment number refers to the order in 783 which the experiments were completed, $\mathbf{S}$ is \% slope of the flume, the discharge $(Q)$ is 784 the estimated discharge $( \pm 5 \%)$ and $\Omega$ is total stream power. The experiments were 785 divided into periods of evolution and experimental runs. Runs were divided into two 8 786 hour blocks, separated by a shorter second round of evolution. The DEM count refers to 787 the number of DEMs used in the reported analysis. Total time is the length of time from 788 the initial straight channel to the end of the final experimental run.

\begin{tabular}{|c|c|c|c|c|c|c|c|c|}
\hline \multirow{2}{*}{ EXPERIMENT } & \multicolumn{3}{|c|}{ INITIAL CONDITIONS } & \multicolumn{2}{|c|}{ EVOLUTION } & \multicolumn{2}{|c|}{ RUNS } & \multirow[b]{3}{*}{ Total Time } \\
\hline & SLOPE & DISCHARGE & STREAM POWER & & Second & & DEM & \\
\hline & $\mathbf{S}$ & $\mathbf{Q}$ & $\mathbf{\Omega}$ & Initial & Round & Time & Count & \\
\hline & $\%$ & $\mid s^{-1}$ & $\mathrm{~W} \mathrm{~m}^{-1}$ & $\mathrm{~h}$ & $\mathrm{~h}$ & $\mathrm{~h}$ & & $\mathrm{~h}$ \\
\hline 1 & 1.5 & 0.70 & 0.10 & 16 & 8 & 16.9 & 29 & 40.9 \\
\hline 4 & 1.5 & 1.65 & 0.24 & 42 & 9 & 17.0 & 66 & 68.0 \\
\hline 9 & 1.5 & 2.10 & 0.31 & 28.25 & 8 & 18.25 & 68 & 54.5 \\
\hline 12 & 1.5 & 2.50 & 0.37 & 20 & 2 & 16.5 & 65 & 38.5 \\
\hline 13 & 2 & 2.10 & 0.41 & 12 & 0.75 & 16.5 & 67 & 29.25 \\
\hline 11 & 1.5 & $0.7-2.1$ & $0.10-0.31$ & 24 & - & 30.25 & 110 & 54.25 \\
\hline Totals & & & & & & 115.4 & 405 & 285.4 \\
\hline
\end{tabular}


789 Table 2 - Vertical error estimates for each experiment based on 1 and 3 standard 790 deviation $(\sigma)$ of the distribution of the elevations for the area of the DEMs that did not 791 undergo morphologic change.

\begin{tabular}{l|ll}
9 & 1.7 & 5.1
\end{tabular}

12

$0.96 \quad 2.88$

13

$0.79 \quad 2.37$

11

793 Table 3 - Summary statistics for average morphological active width as a percent of 794 average wetted width, where $\mathrm{n}$ is the number of observations, $\min$ and $\max$ are the 795 minimum and maximum values, mean is the average, and $\sigma$ is the standard deviation.

\begin{tabular}{c|cccccc}
\multicolumn{7}{c}{ \% ACTIVE WIDTH } \\
\hline \multicolumn{1}{c|}{} & $\mathbf{n}$ & Min & Max & Median & Mean & $\sigma$ \\
1 & 4 & 4.18 & 9.45 & 6.49 & 6.65 & 2.34 \\
4 & 8 & 7.44 & 27.3 & 15.9 & 16.5 & 7.31 \\
9 & 8 & 7.60 & 17.1 & 10.6 & 11.6 & 3.12 \\
12 & 8 & 23.5 & 31.2 & 27.6 & 27.5 & 2.44 \\
13 & 8 & 35.8 & 58.5 & 44.1 & 45.3 & 7.49 \\
11 & 26 & 1.10 & 28.9 & 11 & 11.4 & 8.94
\end{tabular}


796 Table 4 - Summary statistics for bulk change $\left(\mathrm{m}^{3}\right)$ for the constant discharge 797 experiments, where min and max are the minimum and maximum values, mean is the 798 average value, and $\sigma$ is the standard deviation.

\begin{tabular}{c|cccc}
\multicolumn{5}{c}{ BULK CHANGE $\left(\mathbf{m}^{3}\right)$} \\
\hline EXPERIMENT & Minimum & Maximum & Mean & $\sigma$ \\
1 & 0.0000 & 0.0026 & 0.0006 & 0.0005 \\
4 & 0.0024 & 0.0265 & 0.0106 & 0.0056 \\
9 & 0.0061 & 0.0318 & 0.0152 & 0.0059 \\
12 & 0.0232 & 0.0642 & 0.0355 & 0.0081 \\
13 & 0.0343 & 0.0585 & 0.0470 & 0.0058
\end{tabular}


a)
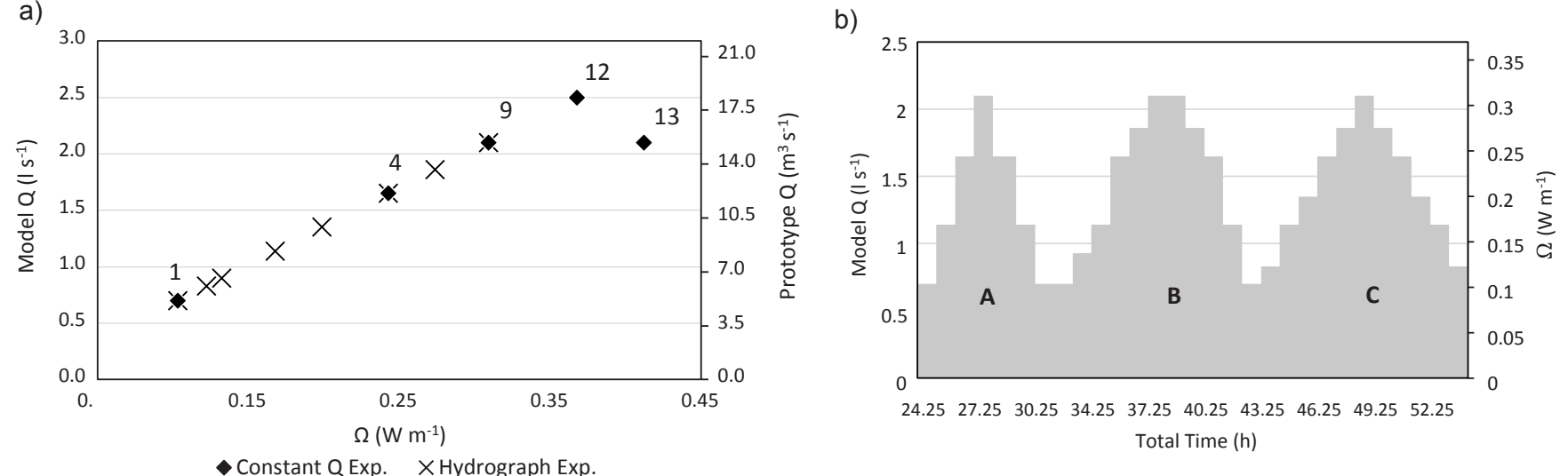

Figure 1 - a) Model discharge ( $Q$ ) and approximate prototype discharge based on 1:35 length scaling as a function of the model total stream power $(\Omega)$ for both the constant discharge and hydrograph experiments.

b) Discharge and total stream power of the model for the hydrograph experiments $(A, B$, and $C)$ as a function of total time. 
Exp. 4

$\mathrm{Q}: 1.65 / \mathrm{s}^{-1}$

$\Omega: 0.24 \mathrm{~W} \mathrm{~m}^{-1}$

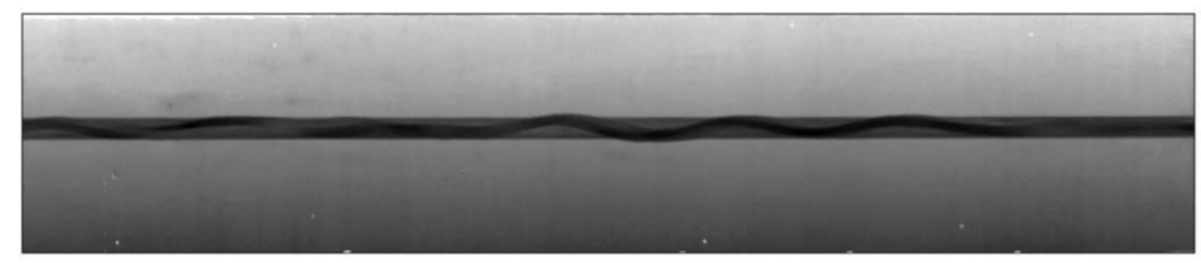

Exp. 9

Q: $2.1 / \mathrm{s}^{-1}$

$\Omega: 0.31 \mathrm{~W} \mathrm{~m}^{-1}$

Exp. 12

Q: $2.5 \mid \mathrm{s}^{-1}$

$\Omega: 0.37 \mathrm{~W} \mathrm{~m}^{-1}$

Exp. 13

Q: $2.1 / \mathrm{s}^{-1}$

$\Omega: 0.41 \mathrm{~W} \mathrm{~m}^{-1}$
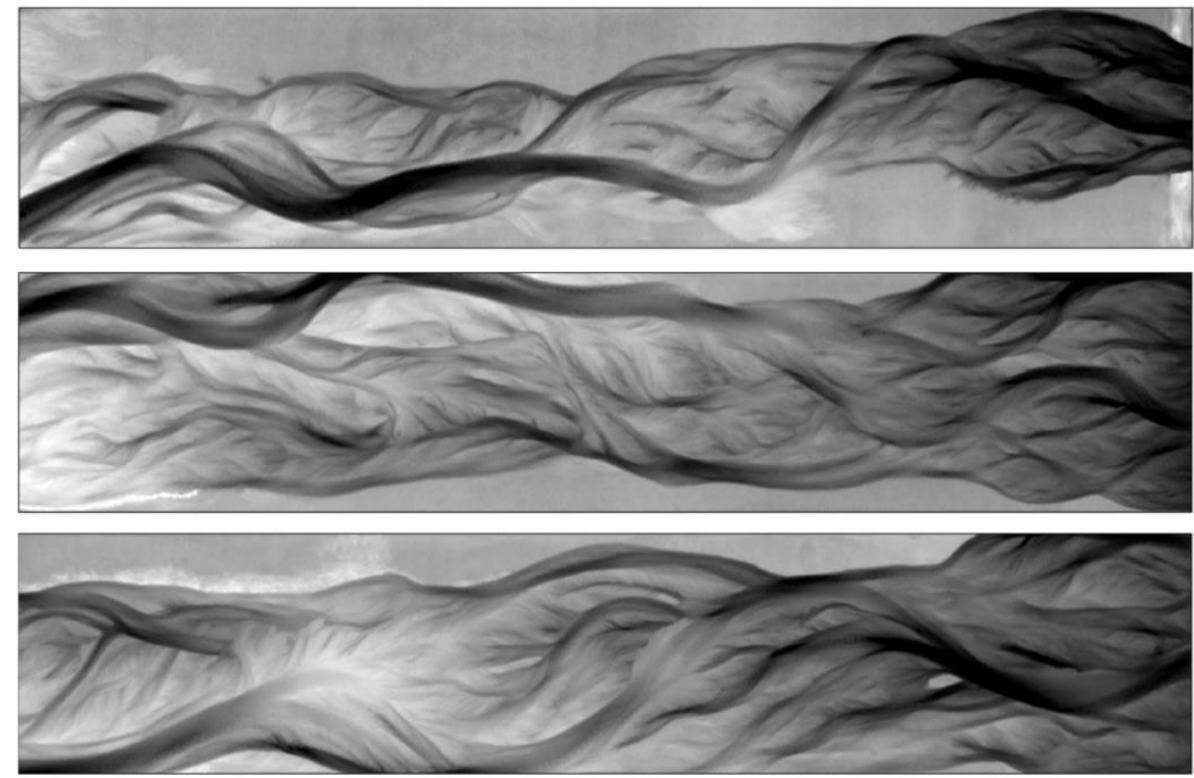

Exp. 11

Q: $0.7-2.1 / \mathrm{s}^{-1}$ $\Omega: 0.10-0.31 \mathrm{~W} \mathrm{~m}^{-1}$
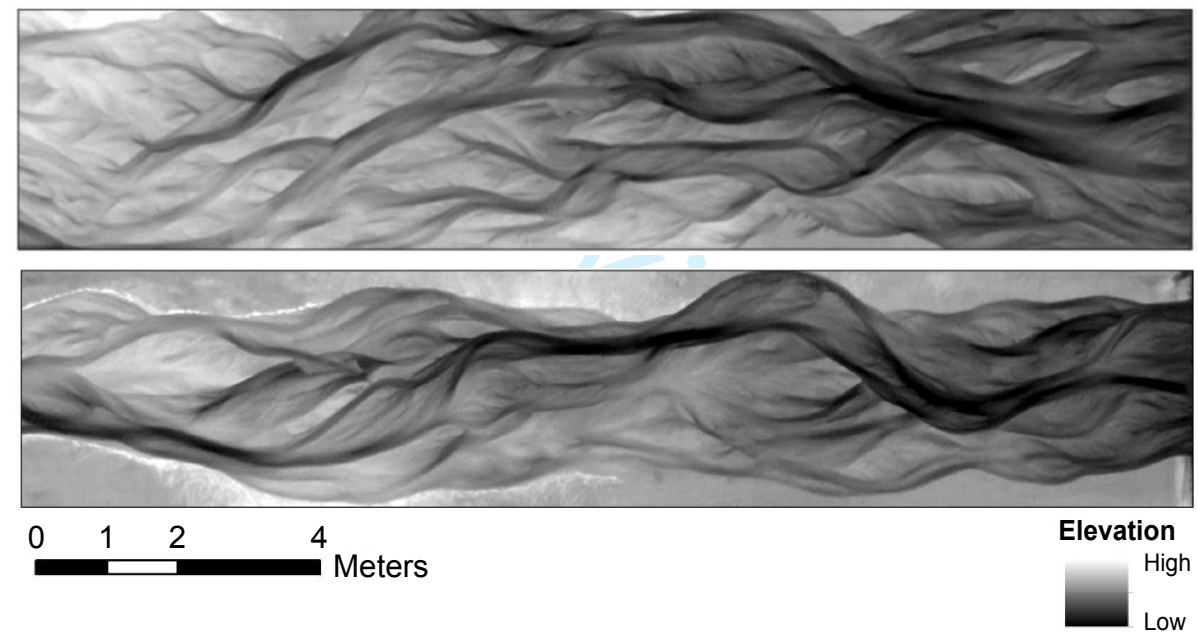

Figure 2 - The final digital elevation models of each experiment, where $Q$ is discharge and $\Omega$ is total stream power. Flow was from left to right. 
Exp. 1

Q: $0.7 / \mathrm{s}^{-1}$

$\Omega: 0.10 \mathrm{~W} \mathrm{~m}^{-1}$

Exp. 9

Q: $2.1 \mathrm{I} \mathrm{s}^{-1}$

$\Omega: 0.31 \mathrm{~W} \mathrm{~m}^{-1}$

Q:1.65 $1 \mathrm{~s}^{-1}$

$\Omega: 0.24 \mathrm{~W} \mathrm{~m}^{-1}$

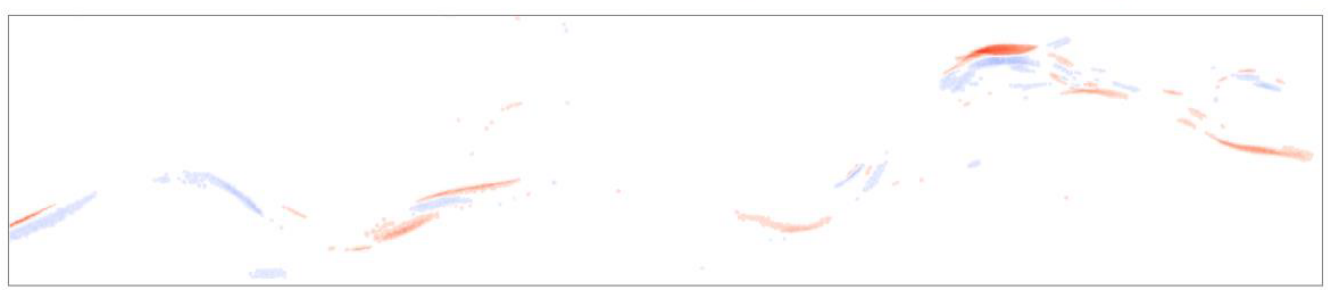

Exp. 12

Q: $2.5 \mid \mathrm{s}^{-1}$

$\Omega: 0.37 \mathrm{~W} \mathrm{~m}^{-1}$

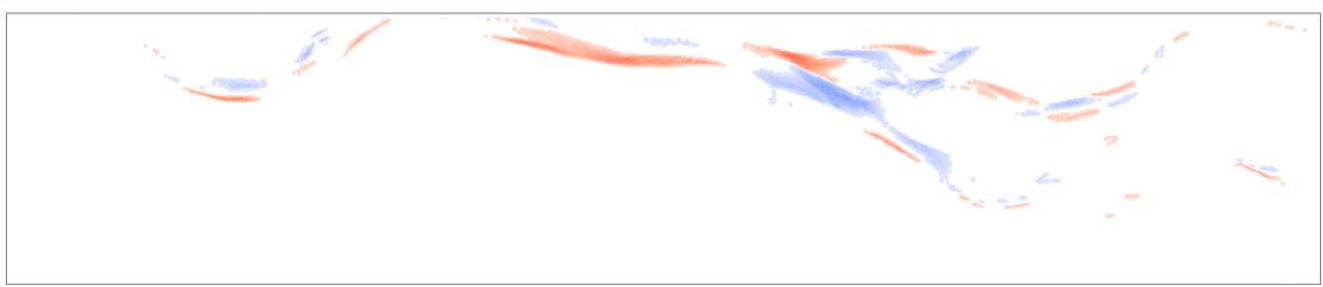

Exp. 13

Q: $2.1 \mathrm{Is}^{-1}$

$\Omega: 0.41 \mathrm{~W} \mathrm{~m}^{-1}$
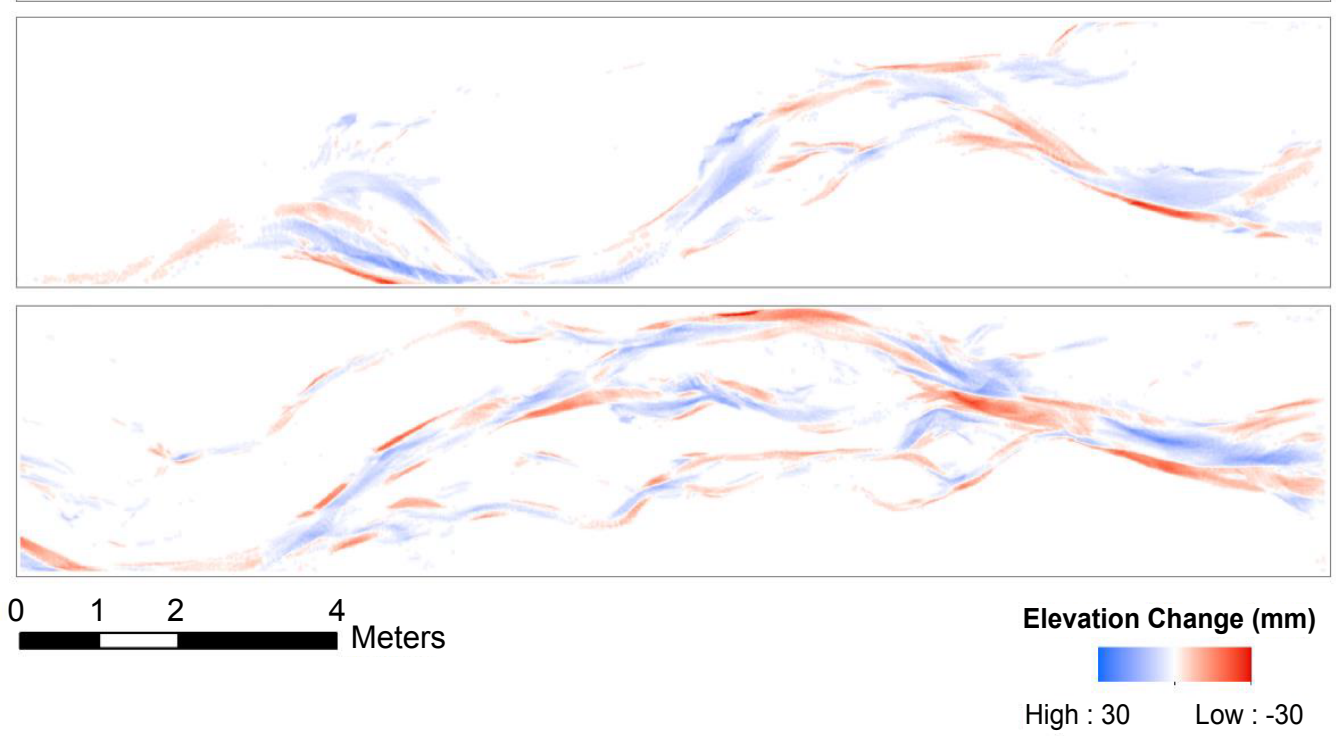

Figure 3 - DEMs of difference generated using the final 2 DEMs from the five constant discharge experiments, where $Q$ is discharge and $\Omega$ is total stream power. Flow was from left to right. 


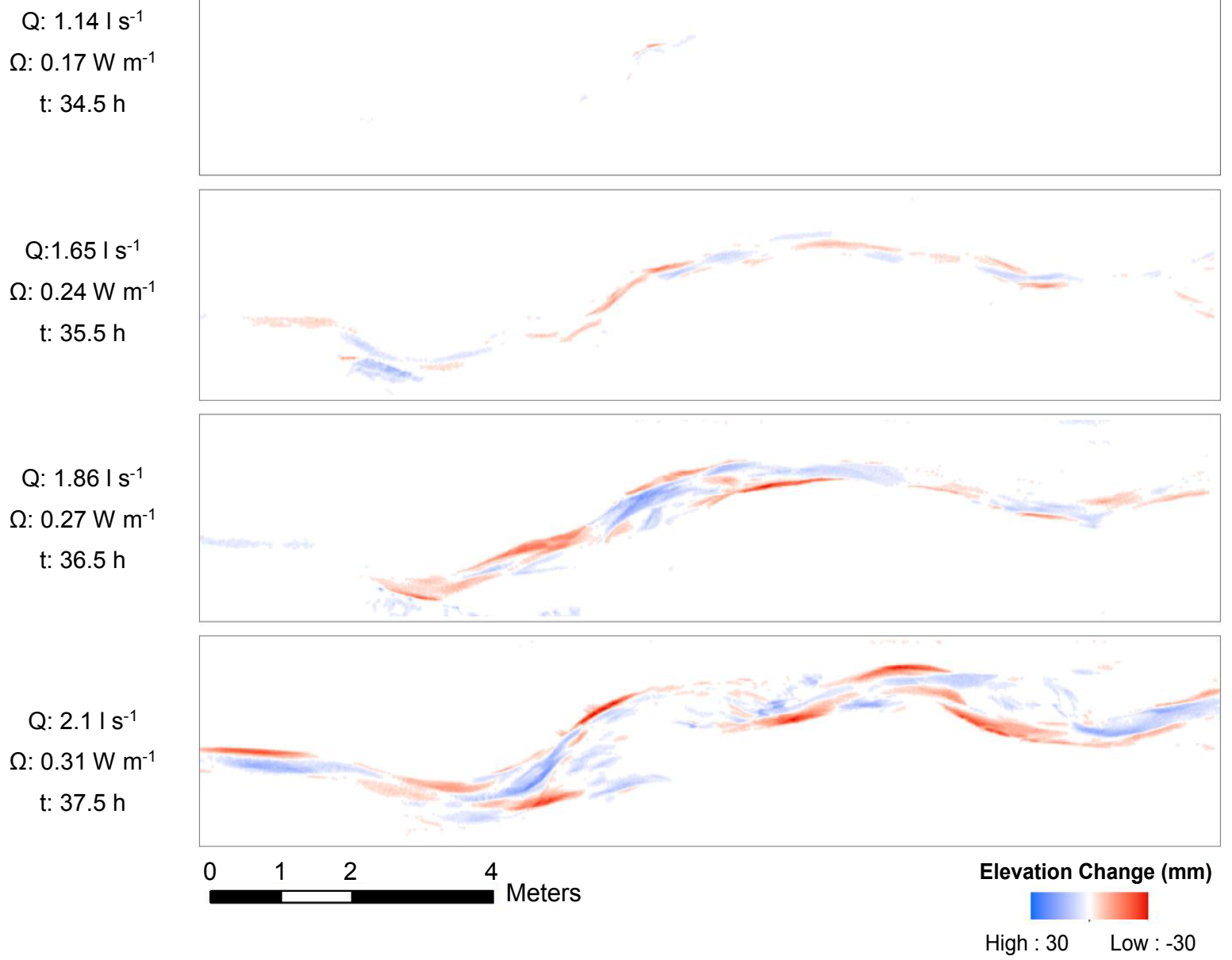

Figure 4 - Example DEMs of difference from the rising limb of hydrograph $B$, experiment 11 , where $Q$ is discharge and $\Omega$ is total stream power, and $t$ refers to total time. Flow is from left to right. 
a)
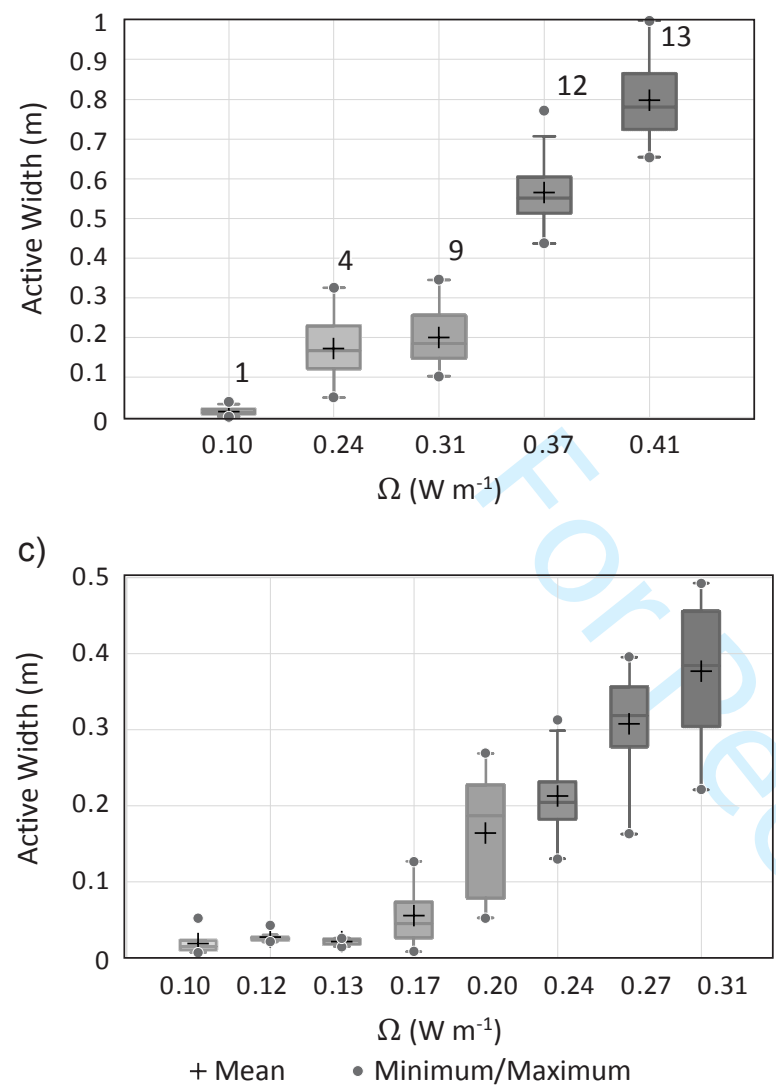

b)

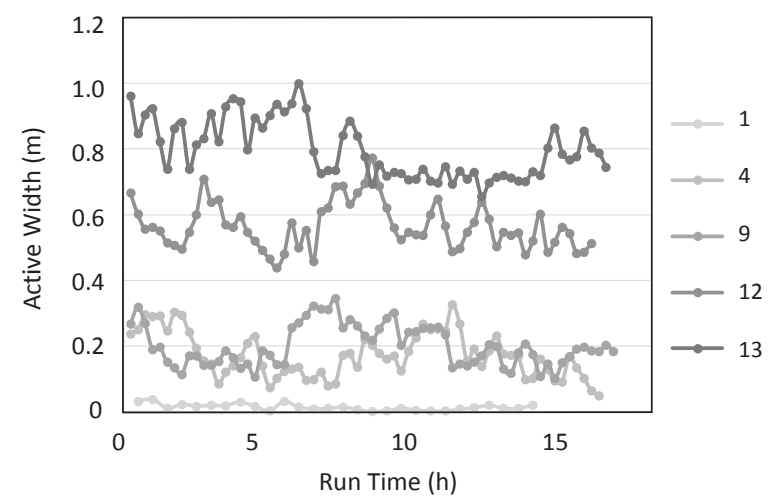

d)

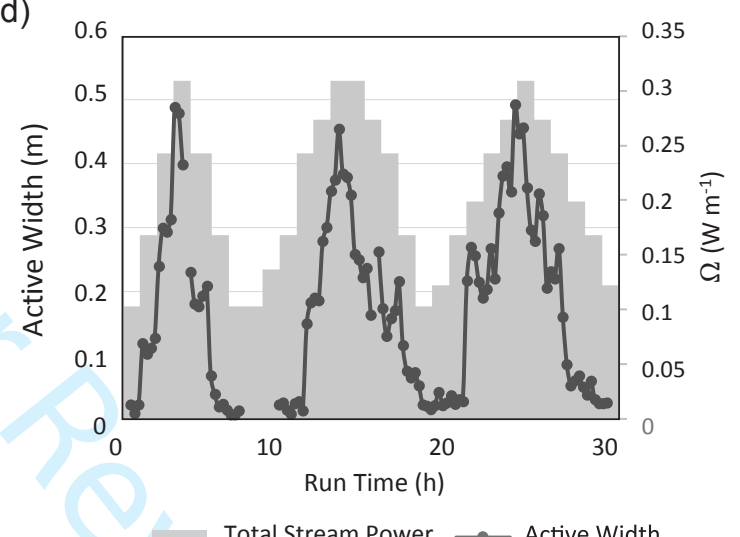

Figure 5 - Reach-averaged morphological active width as a function of total stream power $(\Omega)$ and experimental run time for the constant discharge experiments ( $a$ and $b$ ) and the hydrograph experiments (c and d). 


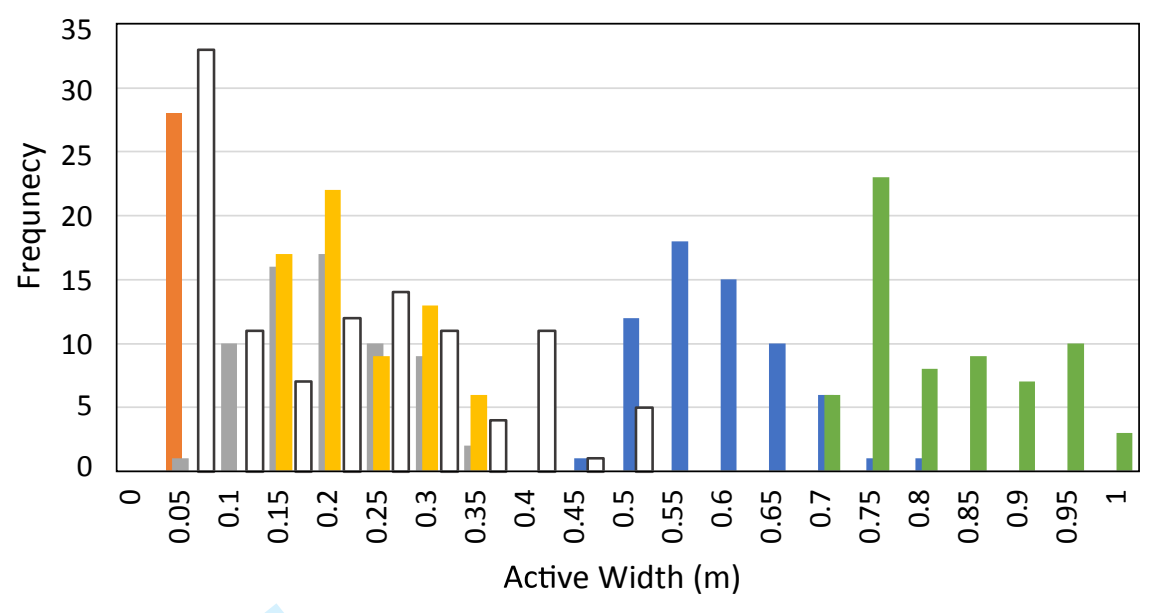

Experiment $\backsim 1 \quad \square 4 \quad \square \quad \square 12 \quad \square 13 \quad \square 11$

Figure 6 - Frequency distributions of the morphological active widths for all the constant discharge $(1,4,9,12$ and 13) and hydrograph (11) experiments. 
a)

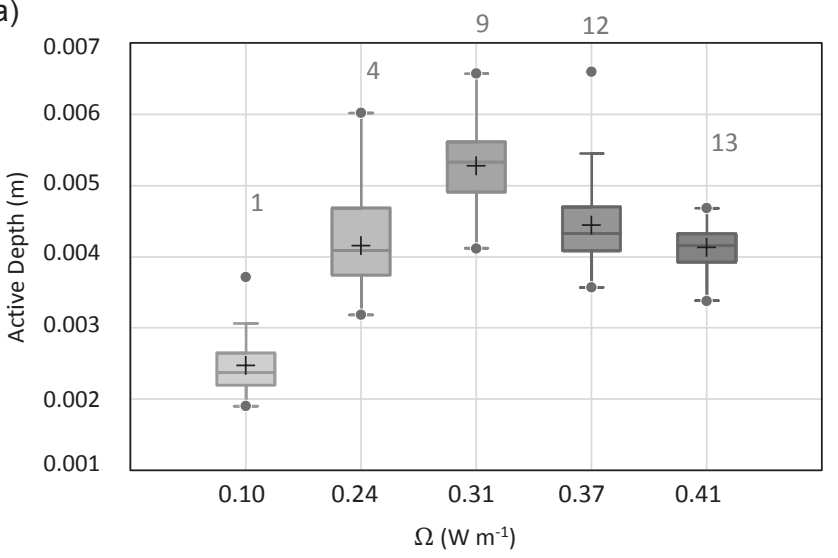

b)

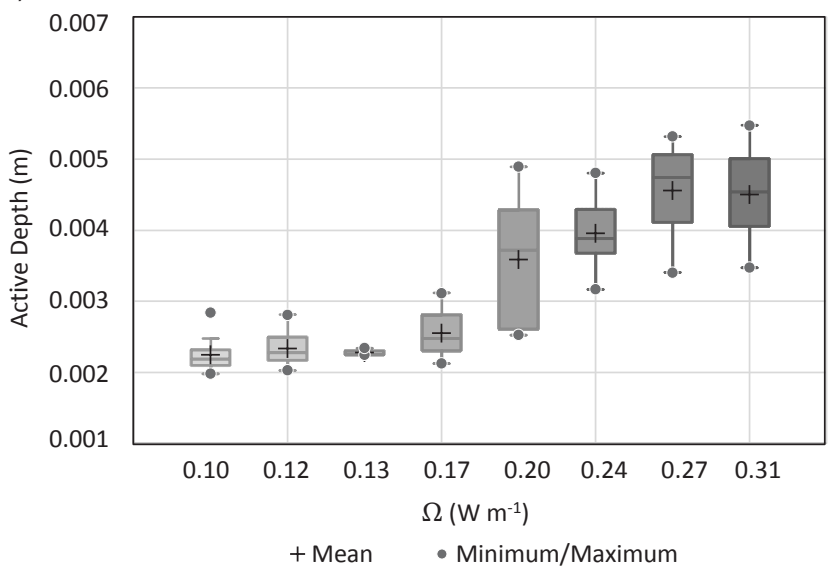

Figure 7 - Reach-averaged morphological active depths versus total stream power $(\Omega)$ for the a) constant discharge $(1,4,9,12$, and 13$)$ and b) hydrograph experiments. 


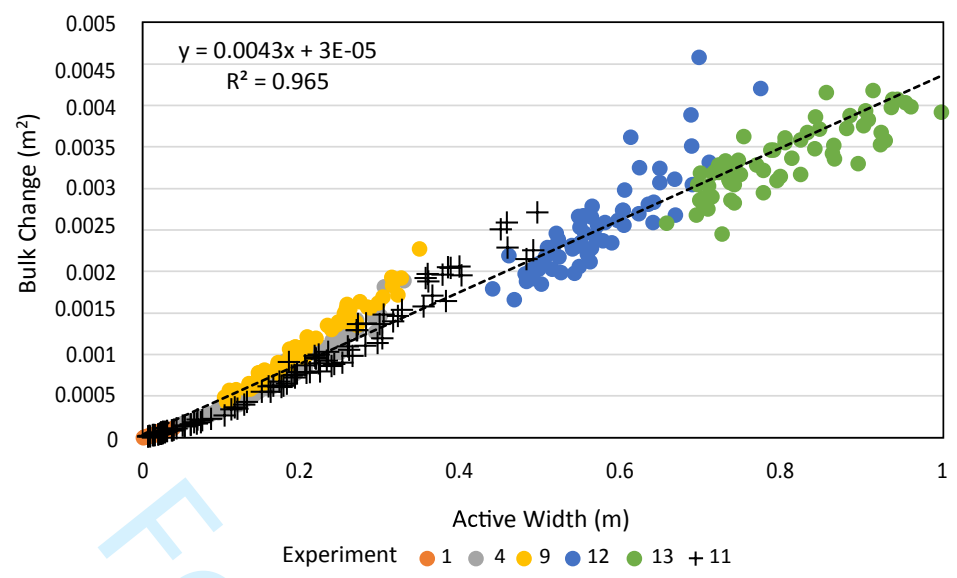

Figure 8 - Reach-averaged bulk change as a function of the reach-averaged morphological active with for the constant discharge $(1,4,9,12$, and 13) and hydrograph (11) experiments. The dashed line represents the linear regression through all observations. 

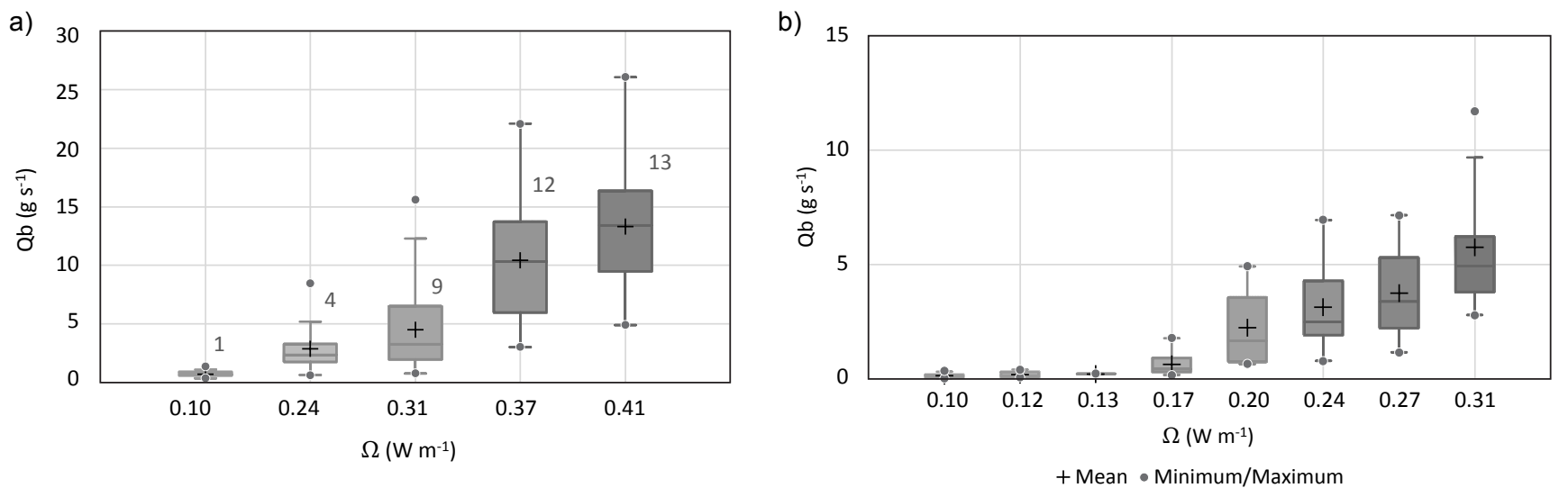

Figure 9 - Bedload transport rates $(\mathrm{Qb})$ for each total stream power $(\Omega)$ of the a) constant discharge $(1,4,9$, 12, and 13) and b) hydrograph experiments. Note differences in axes. 


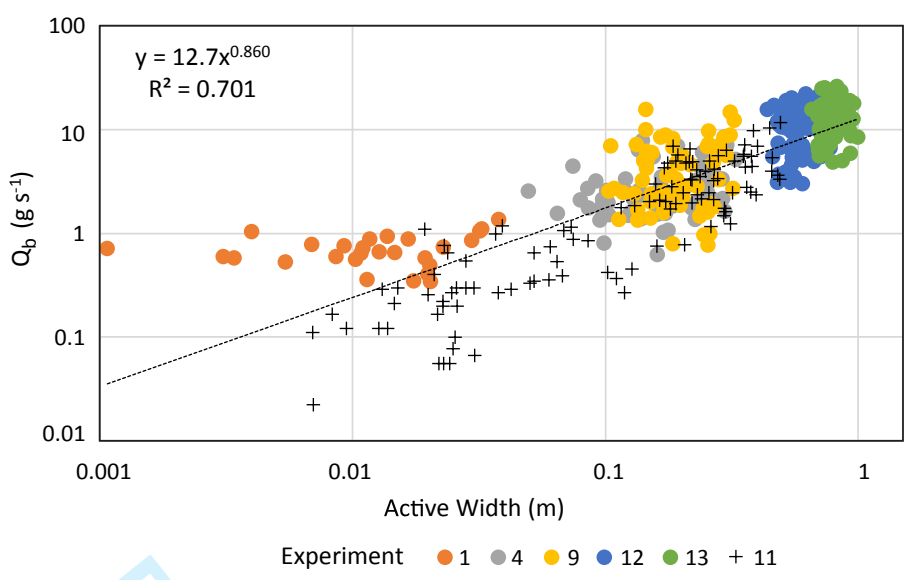

Figure 10 - Bedload transport rate plotted against reach-averaged morphological active width for constant discharge (1, 4, 9, 12 and 13) and hydrograph (11) experiments. The dashed line represents the power regression through all observations. 

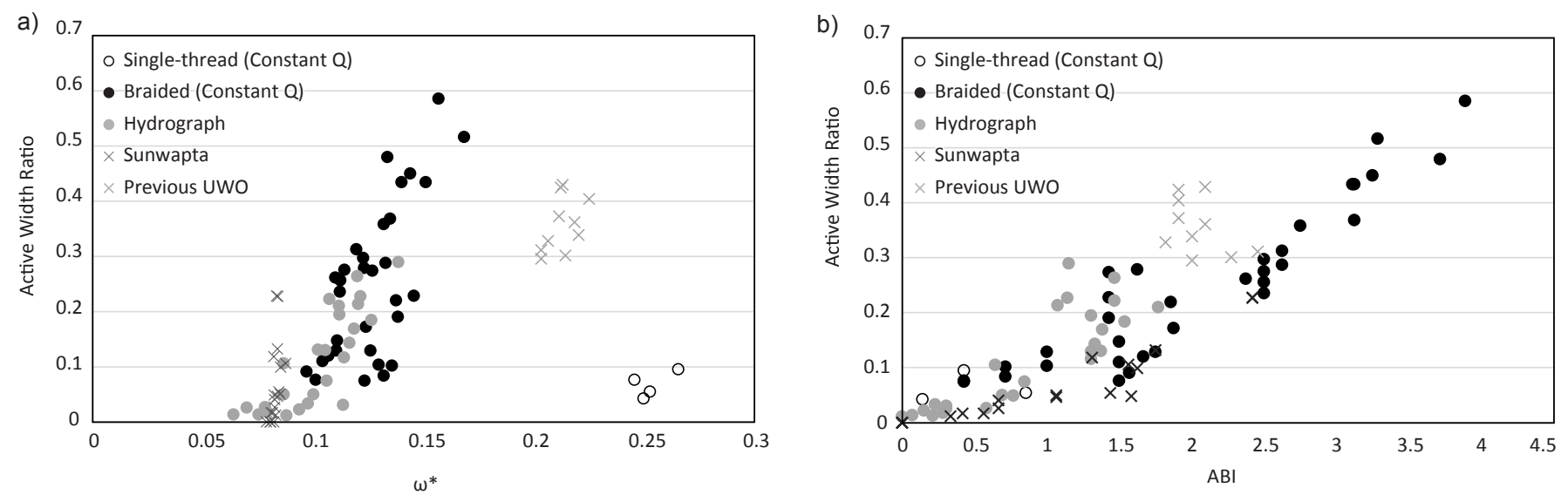

Figure 11 - Reach-averaged morphological active width ratios plotted as a function of a) dimensionless stream power $\left(\omega^{*}\right)$ and $b$ ) active braiding intensity (ABI) combined with field (Sunwapta) and flume (Previous UWO) results from Ashmore et al. (2011), where Q is discharge. 


\section{Graphical Information}

The Variability in the Morphological Active Width: Results from Physical Models of Gravel-Bed Rivers

Sarah Peirce ${ }^{1 *}$, Peter Ashmore $^{1}$, Pauline Leduc ${ }^{1}$

${ }^{1}$ The University of Western Ontario, London, Ontario, Canada

Key Points

- The morphological active width is a fundamental parameter of braided rivers that increases with total and dimensionless stream power.

- The morphological active width has a positive relationship with bulk change, bedload transport, and active braiding intensity.

- Both morphological change and bedload transport rates were largely undetectable under a dimensionless stream power of $\sim 0.09$.

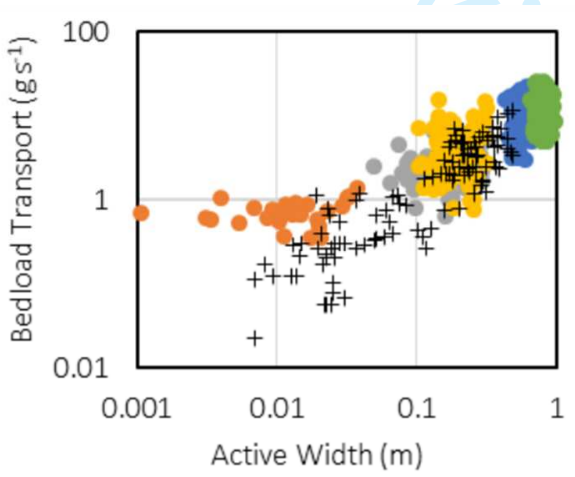

